\title{
Disassembly Study of Ultrasonically Welded Thermoplastic Composite Joints via Resistance Heating
}

\author{
Harry Frederick, Wencai Li and Genevieve Palardy *(D) \\ Department of Mechanical and Industrial Engineering, Louisiana State University, 3261 Patrick F. Taylor Hall, \\ Baton Rouge, LA 70803, USA; hfrede6@lsu.edu (H.F.); wli45@lsu.edu (W.L.) \\ * Correspondence: gpalardy@lsu.edu
}

Citation: Frederick, H.; Li, W.; Palardy, G. Disassembly Study of Ultrasonically Welded Thermoplastic Composite Joints via Resistance Heating. Materials 2021, 14, 2521. https://doi.org/10.3390/ma14102521

Academic Editor: Francesca Lionetto

Received: 19 April 2021

Accepted: 10 May 2021

Published: 12 May 2021

Publisher's Note: MDPI stays neutral with regard to jurisdictional claims in published maps and institutional affiliations.

Copyright: (c) 2021 by the authors. Licensee MDPI, Basel, Switzerland. This article is an open access article distributed under the terms and conditions of the Creative Commons Attribution (CC BY) license (https:/ / creativecommons.org/licenses/by/ $4.0 /)$.

\begin{abstract}
This manuscript explores the disassembly potential of ultrasonically welded thermoplastic composite joints for reuse or recycling through resistance heating via a nanocomposite film located at the welded interface. Nanocomposite films containing multi-walled carbon nanotubes (MWCNTs) were characterized for thermo-electrical behavior to assess self-heating. It was generally observed that maximum temperature increased with MWCNT and film thickness. To demonstrate potential for disassembly, glass fiber/polypropylene adherends were welded with nanocomposite films. Shear stress during disassembly was measured for three initial adherend's surface temperatures. It was found that the required tensile load decreased by over $90 \%$ at the highest temperatures, effectively demonstrating the potential for disassembly via electrically conductive films. Fracture surfaces suggested that disassembly was facilitated through a combination of nanocomposite and matrix melting and weakened fiber-matrix interface. Limitations, such as slow heating rates and the loss of contact at the interface, imply that the method could be more suited for recycling, instead of repair and reuse, as the heat-affected zone extended through the adherends' thickness at the overlap during heating.
\end{abstract}

Keywords: thermoplastic composites; ultrasonic joints; resistance heating

\section{Introduction}

Thermoplastic composites (TPCs) are used in several industries, such as automotive, aerospace, and wind energy, because of their high specific modulus and strength, fracture toughness, damage tolerance, and impact and corrosion resistance [1-4]. Common thermoplastic matrices include polypropylene (PP), polyethylene (PE), and polycarbonate (PC), used in a range of low-cost applications. High-performance thermoplastic matrices encompass higher temperature polymers, such as polyamide 6 (PA6), polyetherimide (PEI), polyphenylene sulfide (PPS), and polyether ether ketone (PEEK) [5]. In addition, Arkema recently developed a liquid thermoplastic resin with similar mechanical properties to thermosetting resins, Elium ${ }^{\circledR}$, which enables the use of composite manufacturing technologies traditionally used for thermosets [6]. As thermoplastics can be thermoformed when heated up above certain temperatures, TPCs have the potential for recycling, reuse and reshaping into new components, as well as joining through fusion bonding [7]. The latter can eliminate the use of rivets, reducing weight, cost and stress concentration. It is more time-efficient than thermoset adhesive bonding because it does not require surface preparation. Fusion bonding is categorized into thermal, electromagnetic and friction welding [3]. Ultrasonic welding (USW) is a technique that has gained momentum in the past few years for TPCs, as it is fast, energy-efficient, and suitable for spot and continuous joining configurations [8-11].

USW joins adherends by the application of high frequency, low amplitude vibrations through a sonotrode (or horn) to generate heat via frictional and viscoelastic mechanisms [12,13]. An "energy director" (ED) must usually be placed at the weld interface to 
concentrate heat generation. Triangular protrusions are typically employed in the plastics industry, but for continuous fiber-reinforced thermoplastics, thin films are also suitable and lead to high strength welds [14-18]. Many studies in the literature experimentally investigated the effect of process parameters (amplitude, force and control mode) and ED geometry on bond quality $[10,14,15,19-26]$ and heat generation $[18,27,28]$. For instance, it was reported that using the vertical displacement of the sonotrode could lead to consistent weld quality using power and displacement curves from the welder. On the other hand, energy director-less welding was found to be possible when controlling the process through time. The prediction of temperature profiles, consumed power, ED flow, and bond strength has shown reasonable accuracy through multi-physics modeling and artificial intelligence methods [13,29-35].

While the USW process and bond strength have been extensively studied for a wide range of TPCs, there is limited research on structural health monitoring and repair of joints. Prior research has shown the potential for multifunctional, nanocomposite films as EDs for USW [36,37]. Those films, rendered electrically conductive by the addition of multiwalled carbon nanotubes (MWCNTs), enabled USW and structural health monitoring at the welded interface through electrical resistance changes. Another function they could fulfill is localized resistance heating at the interface to facilitate disassembly and repair.

Nanocomposite-based heating elements were recently developed and successfully used for the resistance welding of TPCs, notably by Brassard et al. [38,39]. MWCNT/PEI nanocomposite films with weight fractions up to $15 \mathrm{wt} . \%$ led to an electrical conductivity of $0.92 \mathrm{~S} / \mathrm{cm}$. With $10 \mathrm{wt} . \%$ MWCNT, the films reached the glass transition temperature $\left(>217^{\circ} \mathrm{C}\right)$ at an applied voltage of $25 \mathrm{~V}$, demonstrating their Joule heating behavior. However, infrared camera monitoring revealed non-uniform temperature distribution, likely due to copper electrodes acting as heat sinks. In the literature, a wider range of studies on nanocomposite films as susceptors for the induction welding of TPCs or induction heating of adhesives have been carried out. Farahani et al. showed that silver nanoparticle-based thermoplastic films are suitable as susceptors for induction welding, reaching melting temperature in less than $50 \mathrm{~s}$ at $400 \mathrm{~A}[40,41]$. However, the potential for disassembly and the repair of fusion bonded TPC joints has not been investigated in the literature.

Although they have not been used to join TPCs, reversible adhesives were developed to facilitate disassembly and the healing of thermoset composite adherends [42,43]. Those adhesives are made of a thermoplastic matrix, containing ferromagnetic nanoparticles to induce temperature increase through induction heating. Reversible joints provide the benefits of both adhesive and mechanically fastened techniques, including ease of disassembly. The method was demonstrated with acrylonitrile butadiene styrene (ABS) and up to $20 \mathrm{wt} . \%$ ferromagnetic nanoparticles, but is so far limited to fiber-reinforced epoxy composites. This means the adherends would not be significantly affected during the process. In the fusion bonding of TPCs, the disassembly procedure would be expected to affect the adherends, as the bond line is made of the same thermoplastic as the adherends. To the best of the authors' knowledge, disassembly studies on welded TPC joints have not been reported in the literature. Therefore, the aim of this research work is to address this gap by focusing on two particular topics: (1) assess ease of disassembly for ultrasonically welded joints by investigating effect of resistance heating temperature; (2) understand disassembly mechanisms and the extent to which adherends are affected during the process.

This study will demonstrate the potential for disassembly of ultrasonically welded TPC joints via resistance heating. First, the thermo-electrical characterization of MWCNTbased nanocomposite films containing different filler weight fractions was investigated to assess their use as heating elements. Second, ultrasonic welding was used to assemble glass fiber/polypropylene adherends into a single lap joint configuration. Disassembly was carried out with a tensile testing apparatus under a range of applied voltages at the interface, leading to different interface temperatures. Third, the behavior of the joints during the disassembly procedure was analyzed through shear stress and temperature 
curves, fractography analysis and extent of heat-affected zone. Finally, the limitations of this technique and proposed future research directions will be discussed.

\section{Materials and Experimental Methods}

\subsection{Materials}

Polypropylene (PP) masterbatches containing multi-walled carbon nanotubes (MWCNTs) were used for this study. MWCNT loading ratios equal to $15 \mathrm{wt} . \%, 20 \mathrm{wt} . \%$, and $25 \mathrm{wt}$.\% were purchased from Cheap Tubes Inc (Brattleboro, VT, USA). Those specific ratios were selected based on preliminary Joule heating experiments, previous work demonstrating suitability for ultrasonic welding $[36,37]$ and literature on high content CNT-based polymer films for sensing, self-heating and resistance welding [38,39,44,45].

Glass fiber/polypropylene (GF/PP) adherends were used for ultrasonic welding and disassembly testing. GF/PP IE 6030 unitape Polystrand ${ }^{\mathrm{TM}}$ prepregs with a fiber volume fraction of $60 \%$, an areal weight of $461 \mathrm{~g} / \mathrm{m}^{2}$ and a tape thickness of $0.33 \mathrm{~mm}$ were purchased from Avient (formerly PolyOne, Englewood, CO, USA).

\subsection{Nanocomposite Films and Thermoplastic Composites Fabrication}

The nanocomposite films (MWCNT/PP) were manufactured with a heated laboratory press (Dake, Grand Haven, MI, USA). During compression molding, PTFE (polytetrafluoroethylene)-coated fiberglass release films and steel shims were placed between the heated platens to produce a consistent surface finish and to control the films' final thickness. Based on previous work on the effect of ED thickness on USW of TPCs [10,16,46], shims with thicknesses equal to $0.06 \mathrm{~mm}, 0.25 \mathrm{~mm}$ and $0.50 \mathrm{~mm}$ were selected. The molded nanocomposite films were cut into rectangular specimens and stored in sealed bags. For thermo-electrical characterization, the films dimensions were $50 \mathrm{~mm} \times 15 \mathrm{~mm}$, while they were $30 \mathrm{~mm} \times 25 \mathrm{~mm}$ for ultrasonic welding.

GF/PP substrates were manufactured by compression molding with a laboratory press (Dake, Grand Haven, MI, USA). Eight unidirectional prepreg layers, measuring $254 \mathrm{~mm} \times 254 \mathrm{~mm}$, were stacked in a $[0]_{8}$ sequence between steel plates, then placed between the press' heated platens. The laminate was consolidated under $1 \mathrm{MPa}$ at $180{ }^{\circ} \mathrm{C}$ for approximately $15 \mathrm{~min}$. During compression molding, a thermocouple was placed at one edge of the laminate to monitor the temperature between the plies. After demolding, a laminate with a final thickness between $1.8 \mathrm{~mm}$ and $1.9 \mathrm{~mm}$ was obtained. Prior to welding, the laminate was cut into rectangular specimens $(101.6 \mathrm{~mm} \times 25.4 \mathrm{~mm})$ with a water-cooled diamond saw (PICO 155 from Pace Technologies). The longer side was cut along the direction of the glass fibers.

\subsection{Thermo-Electrical Characterization}

Electrical conductivity and the resistance heating measurement setup is illustrated in Figure 1a. A voltage was applied through copper electrodes placed at both ends of the films with a Keithley Sourcemeter 2604B (maximum voltage and current of $40 \mathrm{~V}$ and $1 \mathrm{~A}$, respectively), shown in Figure $1 b, c$. The DC voltages used to gather electrical and thermal data were $1 \mathrm{~V}, 2 \mathrm{~V}, 4 \mathrm{~V}, 6 \mathrm{~V}, 8 \mathrm{~V}$, and $10 \mathrm{~V}$. All film thicknesses were tested $(0.06 \mathrm{~mm}, 0.25 \mathrm{~mm}$, and $0.50 \mathrm{~mm}$ ) to assess their effect on thermo-electrical behavior. The electrical conductivity of the films $\left(\sigma\right.$, in S/cm) was calculated using Equation (1), shown below, where $R_{A v g}$ is the average resistance (in Ohms), $L$ is the length of the film between electrodes (in $\mathrm{cm}$ ), and $A$ is the cross-sectional area of the film (in $\mathrm{cm}^{2}$ ):

$$
\sigma=\frac{L}{R_{A v g} A}
$$


(a)

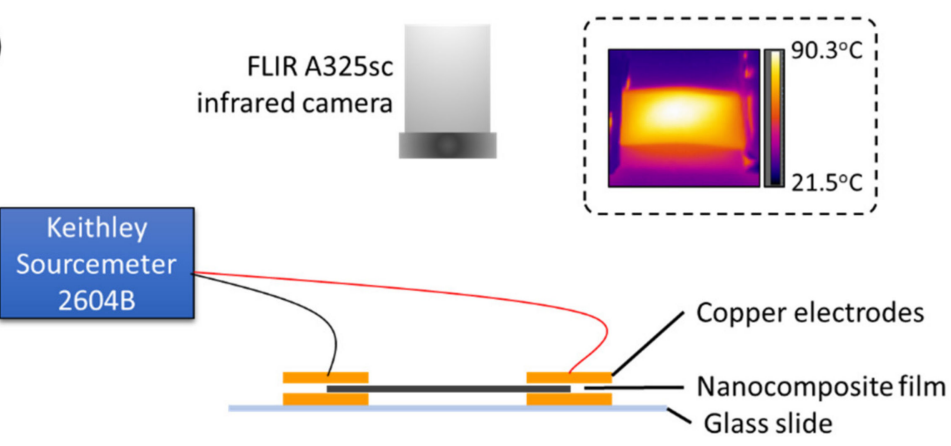

(b)

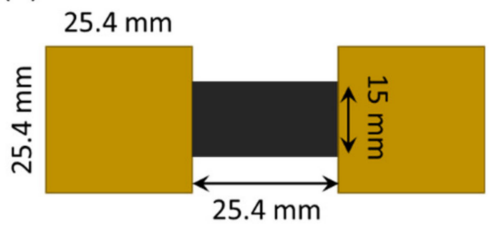

(c)

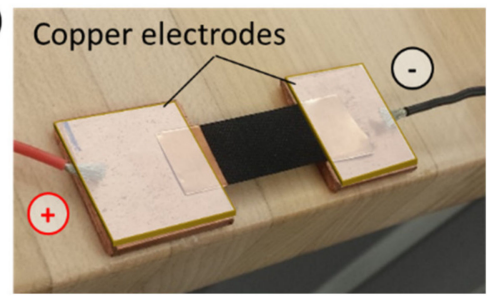

Figure 1. (a) Overall setup used for electrical conductivity and Joule heating measurements. Inset shows representative $2 \mathrm{D}$ temperature plot recorded with infrared camera at $10 \mathrm{~V}$ for a $0.50 \mathrm{~mm}$-thick $20 \mathrm{wt}$ \% MWCNT/PP film after approximately $1 \mathrm{~min}$; (b) copper electrodes and nanocomposite film dimensions; (c) example of actual nanocomposite film and electrodes placement. Dimensions are not to scale.

For resistance heating, each voltage was applied for three minutes with $30 \mathrm{~s}$ between voltages, while the Keithley KickStart software (version 2.0, Beaverton, OR, USA) acquired resistance, power and current data at a rate of 10 data points/second. Two-dimensional temperature plots were acquired with a FLIR A325sc infrared camera (FLIR Systems, Spicewood, TX, USA) placed above the film, at a rate of $15 \mathrm{~Hz}$ (example shown in Figure 1a in inset). Temperature profiles were extracted at the center of the film. For each applied voltage, MWCNT weight fraction and film thickness, seven to ten samples were tested.

\subsection{Ultrasonic Welding Procedure}

GF/PP adherends were welded in a single lap configuration with an overlap area of $25.4 \mathrm{~mm} \times 12.7 \mathrm{~mm}$. A Dynamic 3000 ultrasonic welder (Rinco Ultrasonics, Danbury, CT, USA) with a maximum power of $3000 \mathrm{~W}$ and a constant operating frequency of $20 \mathrm{kHz}$ was used with a $40 \mathrm{~mm}$ diameter titanium sonotrode. The booster and sonotrode gains were 1:1.5 and 1:3.85, respectively. Both adherends were clamped with aluminum bars and M8 socket head screws on a baseplate, as shown in Figure 2a,b. A nanocomposite film was placed between the adherends to act as the energy director. Films containing $15 \mathrm{wt} . \%, 20 \mathrm{wt} . \%$, and $25 \mathrm{wt} . \%$ MWCNT with a thickness of $0.50 \mathrm{~mm}$ were used. Even though thermo-electrical characterization was performed on three different thicknesses, the thickest films were selected for welding and disassembly because they led to the highest bond line thickness, as will be discussed in Section 4.1.1. 


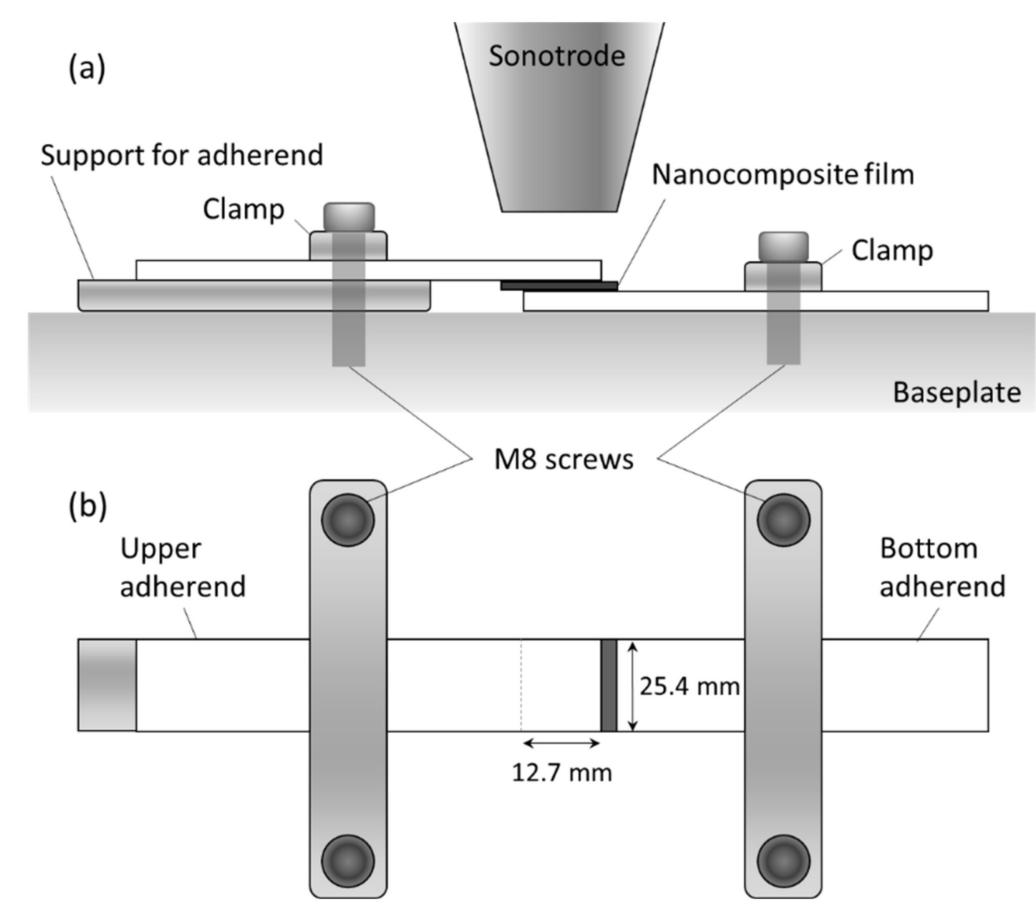

Figure 2. Schematic of ultrasonic welding fixture used in this study for GF/PP adherends and MWCNT/PP energy director films: (a) side view and (b) top view. Dimensions are not to scale.

For all welds, during the vibration phase, a force of $1000 \mathrm{~N}$ and an amplitude of $38.1 \mu \mathrm{m}$ were applied. The duration of the vibration phase was controlled through the vertical displacement of the sonotrode (also called "travel") until it reached a value equal to $60 \%$ of the initial films' thickness. After reaching the prescribed travel value, a consolidation force of $1000 \mathrm{~N}$, for a duration of $4 \mathrm{~s}$, was applied. Those welding parameters were chosen based on previous research [36,37]. The power and travel curves with respect to welding time were acquired for each weld.

\subsection{Disassembly of Welded Joints}

Following ultrasonic welding, excess polymer at the interface edges was removed with a razor blade. Two $30 \mathrm{AWG}$ copper wires were connected at the interface with silver paint (SPI \#05002-AB, electrical resistivity of $1.2 \times 10^{-4} \mathrm{Ohms} \cdot \mathrm{cm}$ ) to maximize electrical contact. Painted wires and interface were dried overnight before disassembly experiments.

In order to quantify the shear stress required to disassemble the welded joints, the samples were tested with a $50 \mathrm{kN}$ tensile machine (TestResources 313, TestResources Inc., Shakopee, MN, USA), according to ASTM D1002. A schematic of the test setup is shown in Figure 3. The specimens were clamped between hydraulic grips at a distance of $60 \mathrm{~mm}$. The position of both grips was adjusted so that the load direction was aligned with the overlap direction. A voltage between $14 \mathrm{~V}$ and $20 \mathrm{~V}$ was applied while monitoring the surface temperature of the GF/PP adherend with a FLIR A325sc infrared camera (FLIR Systems, Spicewood, TX, USA). While an external monitoring method does not provide the same accuracy as an embedded sensor at the interface, it was selected for two reasons: (1) the ultrasonic welding process may affect the position and integrity of embedded sensors at the interface due to ultrasonic vibrations (e.g., thermocouples or fiber optic sensors); (2) temperature measurements might become inaccurate as failure initiation and propagation occurs at the interface. Disassembly was initiated at a loading rate of $1.3 \mathrm{~mm} / \mathrm{min}$ when the surface temperature reached either $110^{\circ} \mathrm{C}, 130^{\circ} \mathrm{C}$, or $150{ }^{\circ} \mathrm{C}$ at the center point of the $25.4 \mathrm{~mm} \times 12.7 \mathrm{~mm}$ overlap (delineated by a red, dashed rectangle in Figure 3). Those three temperature values were selected based on simplified 3D thermal analyses, detailed in Section 3 of this manuscript. After disassembly, the extent of the heat-affected zone (HAZ) was quantified using image analysis with the ImageJ software 
(National Institutes of Health, NIH, version 1.53e, Bethesda, MD, USA). The HAZ area was measured and its \% value was calculated with respect to the overlap area.

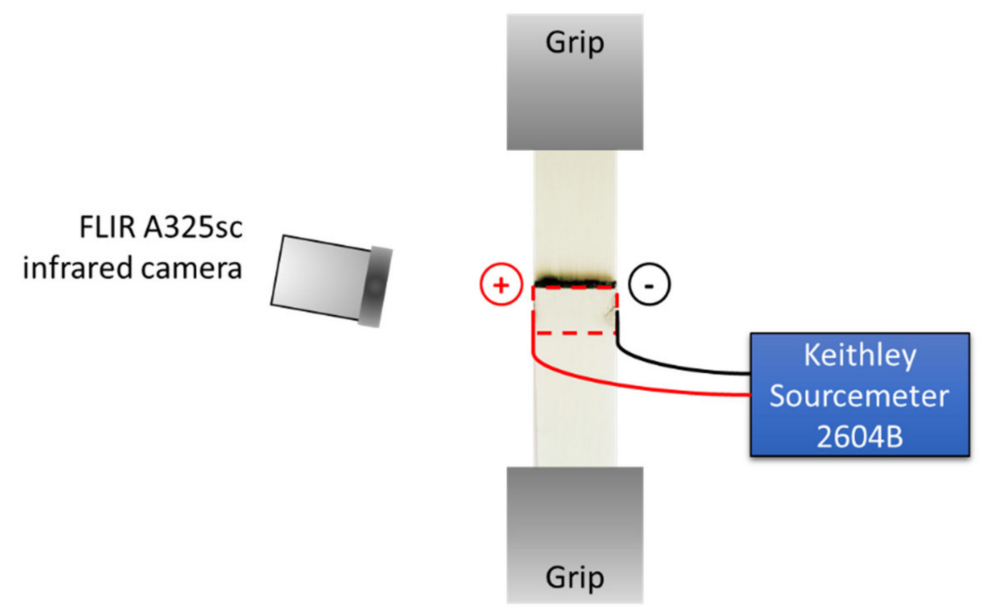

Figure 3. Disassembly setup with infrared camera and sourcemeter. The dashed rectangle indicates the surface area that was monitored for temperature during the tests. Not to scale.

\subsection{Scanning Electron Microscopy (SEM)}

After disassembly, the microstructure of the fracture surfaces was observed through SEM. Surfaces were coated with gold using a sputter coater (EMS550X, Electron Microscopy Sciences, Hatfield, PA, USA) under a vacuum of $10^{-1} \mathrm{mbar}$, at $25 \mathrm{~mA}$ for $2 \mathrm{~min}$. A highperformance JSM-6610LV SEM (JEOL Ltd., Tokyo, Japan) was employed to capture images, at an acceleration voltage of $15 \mathrm{kV}$.

\section{Prediction of Heat-Affected Zone for Disassembly Experiments}

Despite the low thickness of the bond line $(\leq 0.50 \mathrm{~mm})$ and adherends $(<1.90 \mathrm{~mm})$, a lag was expected between the surface temperature and the actual temperature at the welded interface. A simplified 3D thermal analysis was carried out in the SolidWorks Thermal Simulation module to predict the temperature at the surface of the adherend (as shown in Figure 3) for various interface temperatures. The goal of these analyses was to provide a range of surface temperatures that would guide the design of the disassembly experiments, based on material properties from the suppliers and found in the literature.

Figure 4a shows the boundary conditions for the thermal finite element analysis (FEA). The thickness of the bond line was $0.1 \mathrm{~mm}$ (half-thickness of MWCNT/PP interface) and the GF/PP adherend was $1.8 \mathrm{~mm}$ thick. A forced air convection coefficient of $12 \mathrm{~W} / \mathrm{m}^{2} \cdot \mathrm{K}$ was selected for the room in which tests were to be carried out. It was applied to all adherend surfaces in contact with air. The contact between ED and adherend was defined as "Bonded". The temperature at the interface was set at three values: $120^{\circ} \mathrm{C}, 140{ }^{\circ} \mathrm{C}$ or $160^{\circ} \mathrm{C}$, based on the melting temperature of GF/PP adherends and MWCNT/PP films, between $140{ }^{\circ} \mathrm{C}$ and $150{ }^{\circ} \mathrm{C}$ [36]. Due to the orthotropic behavior of the adherends (UD layup), two thermal conductivity values $\left(k_{y}, k_{x}=k_{z}\right)$ were estimated using the rule of mixture shown in Equation (2) and Equation (3):

$$
\begin{gathered}
k_{y}=\left(1-V_{G F}\right) k_{P P}+V_{G F} k_{G F}, \\
\frac{1}{k_{x, z}}=\frac{\left(1-V_{G F}\right)}{k_{P P}}+\frac{V_{G F}}{k_{G F}}
\end{gathered}
$$

where $V_{G F}$ is the glass fiber volume fraction, $k_{P P}$ is the thermal conductivity of polypropylene (in $\mathrm{W} / \mathrm{m} \cdot \mathrm{K}$ ) and $k_{G F}$ is the thermal conductivity of glass fibers (in $\mathrm{W} / \mathrm{m} \cdot \mathrm{K}$ ). The material properties for the GF/PP adherends are listed in Table 1 . The heat capacity, $C_{p}$ (in $\mathrm{J} / \mathrm{kg} \cdot \mathrm{K}$ ), was calculated based on the rule of mixture, as described in Equation (2). 
The MWCNT/PP films were assumed to exhibit isotropic properties with random carbon nanotubes orientation and distribution. The main thermal properties are listed in Table 1 with the corresponding references in the literature. The nanocomposite films' thermal conductivity was estimated to range between $0.55 \mathrm{~W} / \mathrm{m} \cdot \mathrm{K}$ and $0.65 \mathrm{~W} / \mathrm{m} \cdot \mathrm{K}$ based on $[47,48]$, to account for MWCNT weight fraction and potential variations in dispersion.
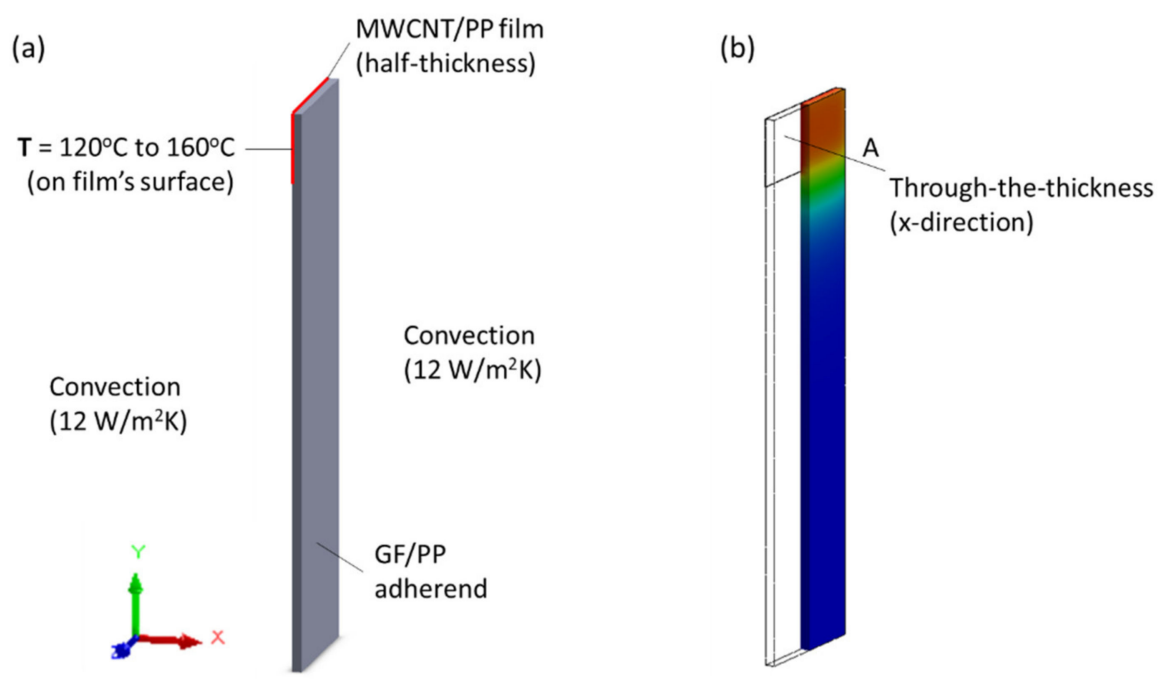

Figure 4. (a) Boundary conditions for finite element analysis used for prediction of temperature profile through the thickness of GF/PP joint. Symmetry was assumed along the ZY plane; and (b) Example of 3D thermal plot with location of plotted results at the mid-plane, along $\mathrm{x}$-direction at center of bond line.

Table 1. Main estimated GF/PP adherend and MWCNT/PP films thermal properties used in FEA. Refer to Figure 4a for coordinate system.

\begin{tabular}{cccccc}
\hline \multicolumn{7}{c}{$\mathrm{GF} / \mathrm{PP}$} \\
\hline $\begin{array}{c}V_{G F} \\
(\%)\end{array}$ & $\begin{array}{c}k_{G F} \\
(\mathrm{~W} / \mathrm{m} \cdot \mathrm{K})\end{array}$ & $\begin{array}{c}k_{P P} \\
(\mathrm{~W} / \mathrm{m} \cdot \mathrm{K})\end{array}$ & $\begin{array}{c}k_{y} \\
(\mathrm{~W} / \mathrm{m} \cdot \mathrm{K})\end{array}$ & $\begin{array}{c}k_{x}, k_{z} \\
(\mathrm{~W} / \mathrm{m} \cdot \mathrm{K})\end{array}$ & $\begin{array}{c}C_{p} \\
(\mathrm{~J} / \mathrm{kg} \cdot \mathrm{K})\end{array}$ \\
\hline $60^{\mathrm{a}}$ & $1.05^{\mathrm{b}}$ & $0.15^{\mathrm{a}}$ & 0.69 & 0.31 & 1.22 \\
\hline \multicolumn{7}{c}{$\mathrm{MWCNT} / \mathrm{PP}$} \\
$\begin{array}{c}\text { MWCNT wt } \\
(\%)\end{array}$ & $\begin{array}{c}k_{C N T} \\
(\mathrm{~W} / \mathrm{m} \cdot \mathrm{K})\end{array}$ & $\begin{array}{c}k_{P P} \\
(\mathrm{~W} / \mathrm{m} \cdot \mathrm{K})\end{array}$ & $\begin{array}{c}k_{\mathrm{CNT} / P P} \\
(\mathrm{~W} / \mathrm{m} \cdot \mathrm{K})\end{array}$ & $\begin{array}{c}C_{p} \\
(\mathrm{~J} / \mathrm{kg} \cdot \mathrm{K})\end{array}$ \\
\hline $15 / 20 / 25$ & $3000^{\mathrm{c}}$ & $0.15^{\mathrm{a}}$ & 0.55 to $0.65^{\mathrm{c}}$ & \multicolumn{2}{c}{$1.50^{\mathrm{c}}$} \\
\hline
\end{tabular}

a: Suppliers' specifications sheet (PolyOne and Professional Plastics); b: [5]; c: [47,48].

Figure 5 shows the through-the-thickness temperature profiles along line $\mathrm{A}$ at the cross-section labeled in Figure 4b. The results for $15 \mathrm{wt} . \%$ MWCNT/PP film at the bond line are presented, but no significant differences were found for the range of $k_{C N T / P P}$ values in Table 1. The surface temperature at the center point of the overlap is $112.8^{\circ} \mathrm{C}, 131.3^{\circ} \mathrm{C}$ and $149.9^{\circ} \mathrm{C}$ for an interface temperature of $120^{\circ} \mathrm{C}, 140{ }^{\circ} \mathrm{C}$ and $160^{\circ} \mathrm{C}$, respectively. Given a temperature gradient around $10^{\circ} \mathrm{C}$, as well as the assumptions and simplifications made for thermal analysis, it was estimated that the disassembly experiments should be carried out when the surface temperature of the GF/PP adherend reached $110^{\circ} \mathrm{C}, 130{ }^{\circ} \mathrm{C}$ and $150{ }^{\circ} \mathrm{C}$ to adequately capture the behavior of the heated joint. 


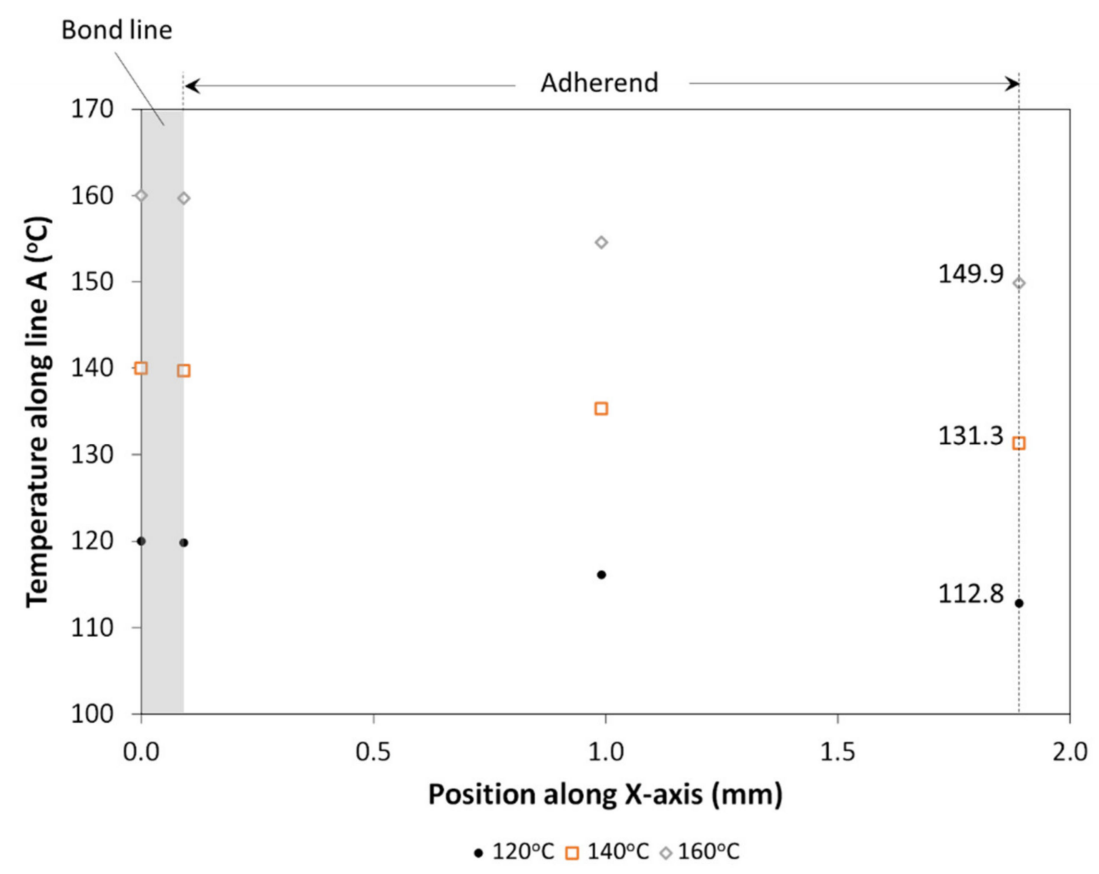

Figure 5. Predicted through-the-thickness temperature profiles along line $\mathrm{A}$ at the cross-section labeled in Figure $4 \mathrm{~b}$ when interface is set at a temperature of $120^{\circ} \mathrm{C}, 140{ }^{\circ} \mathrm{C}$ and $160{ }^{\circ} \mathrm{C}$. The bond line material was $15 \mathrm{wt} . \% \mathrm{MWCNT} / \mathrm{PP}$.

\section{Experimental Results and Discussion}

\subsection{Nanocomposite Films Characterization}

\subsubsection{Electrical Conductivity}

Figure 6a shows results for electrical conductivity measurements of nanocomposite PP films containing 15 wt. \%, 20 wt.\%, and 25 wt.\% MWCNT, across all three thicknesses. Overall, values are in the same order of magnitude as previously observed in the literature for MWCNT/PP films [49-51], as well as for nanocomposite heating elements designed for resistance welding with weight fractions above 10 wt.\% MWCNT [39]. Two general trends are observed. First, for the same applied voltage, average conductivity generally increased with CNT weight fraction, more prominently at $1 \mathrm{~V}$ and $2 \mathrm{~V}$. Second, for the same weight fraction, conductivity increased with applied voltage, which indicates non-ohmic behavior. This is consistent with the literature, where it was observed that MWCNT nanocomposites exhibit tunneling conductive mechanisms, where a stronger applied electric field creates more conductive pathways through the material [52].

However, due to the large standard deviation caused by the variation in resistance measurements during this time period, statistical significance between means at different voltages and weight fractions was assessed using a two-way analysis of variance (ANOVA), followed by Tukey's multiple comparison test. The software GraphPad Prism 9.1.0 was used to carry out statistical analyses. The level of significance was set at $p<0.05$. At $1 \mathrm{~V}$ and $2 \mathrm{~V}$, the only significant comparisons $(p<0.05)$ were between $15 \mathrm{wt} . \%$ and $25 \mathrm{wt} . \% \mathrm{MWCNT}$. At all other voltages, $20 \mathrm{wt}$.\% versus $25 \mathrm{wt}$ \% MWCNT was significant. For the same wt.\% value, the main ANOVA outcomes can be summarized as follows: no significance was determined between $1 \mathrm{~V}$ and $2 \mathrm{~V}$, then between $6 \mathrm{~V}$ and $8 \mathrm{~V}, 6 \mathrm{~V}$ and $10 \mathrm{~V}$, and $8 \mathrm{~V}$ and $10 \mathrm{~V}$. Other comparisons between $1 \mathrm{~V}$ vs. $4 \mathrm{~V}, 6 \mathrm{~V}, 8 \mathrm{~V}$ and $10 \mathrm{~V}$, between $2 \mathrm{~V}$ vs. $6 \mathrm{~V}, 8 \mathrm{~V}$ and $10 \mathrm{~V}$, then between $4 \mathrm{~V}$ vs. $8 \mathrm{~V}$ and $10 \mathrm{~V}$, were determined to be significant. Thus, this confirms the general increasing trend with MWCNT weight fraction and applied voltage. 

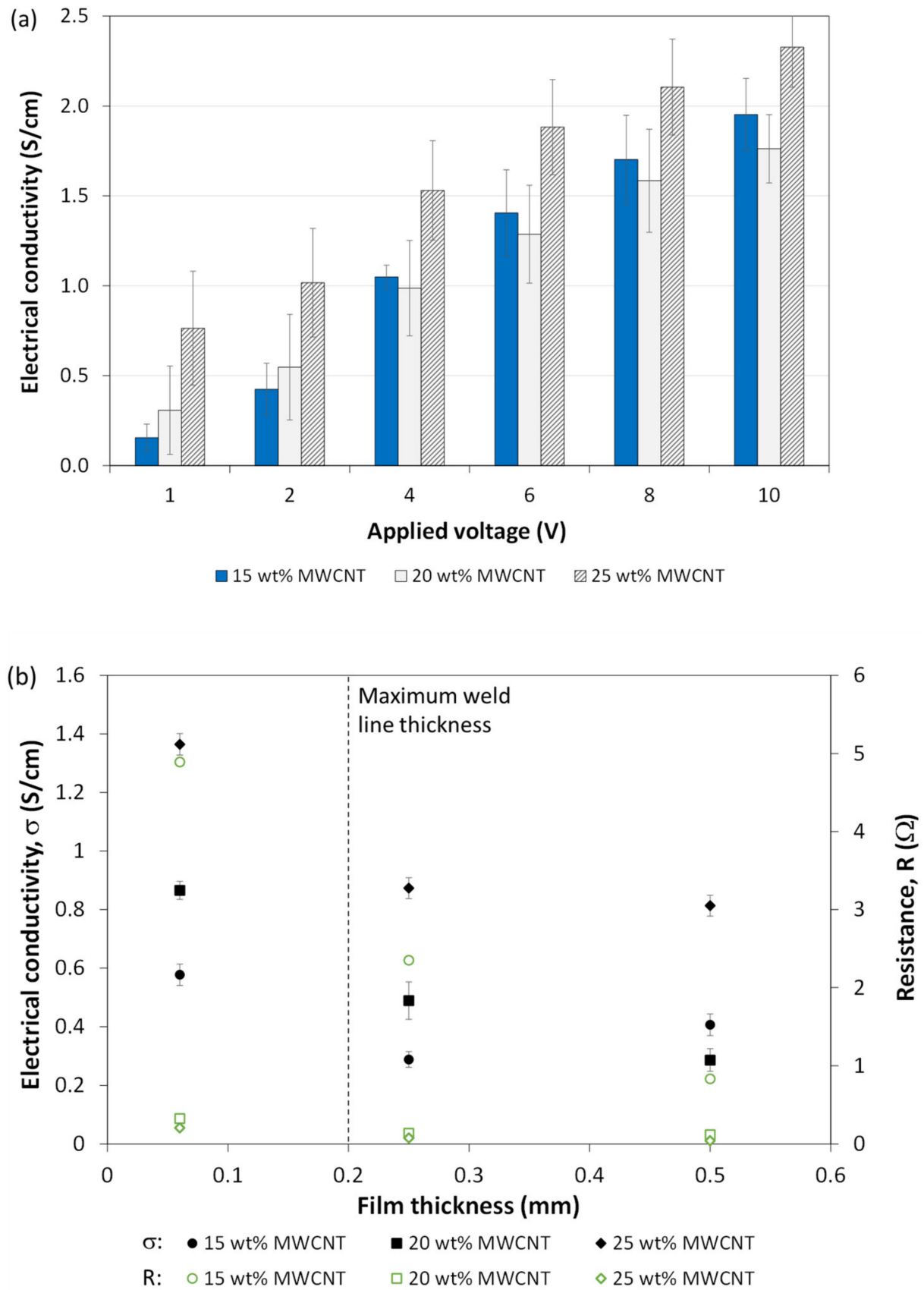

Figure 6. (a) Influence of applied voltage on average film electrical conductivity for $15 \mathrm{wt} . \%, 20 \mathrm{wt} . \%$ and 25 wt.\% MWCNT; (b) influence of film thickness on electrical conductivity (filled markers) and resistance (unfilled markers) for $15 \mathrm{wt} . \%, 20 \mathrm{wt} . \%$ and $25 \mathrm{wt} . \%$ MWCNT. Representative data shown when voltage of $2 \mathrm{~V}$ was applied.

The effect of film thickness was assessed separately and a representative plot is shown in Figure $6 \mathrm{~b}$ at an applied voltage of $2 \mathrm{~V}$. Thickness is especially important with respect to the welding process as it is controlled through the vertical displacement (travel). In our study, a travel equal to $60 \%$ of the initial film thickness $(0.50 \mathrm{~mm})$ was used, meaning the final bond line thickness would be equal to $0.20 \mathrm{~mm}$ at most. For all MWCNT fractions, the general trend shows a decrease in conductivity with an increase in film thickness. This is opposite to what was observed in the literature for CNT/PDMS nanocomposites prepared with a centrifugal mixer [53]. However, the fabrication method used in our study, compression molding, can explain this behavior. As no additional mechanical mixing or solvent-based dissolution was employed, the CNT dispersion is likely not perfectly 
random and uniform across the thickness. This may affect the density of the conducting channels in the CNT network and in turn, the electrical conductivity.

Corresponding resistance values are reported in Figure $6 \mathrm{~b}$ as well. As will be explained in Section 4.1.2, lower resistance leads to higher temperature increase through Joule heating. This indicates that higher MWCNT fractions or thicknesses would allow for reaching higher temperatures for the same applied voltage. Based on the trend shown in Figure 6b, a higher thickness at the weld line would be preferable for the disassembly procedure to insure the desired temperatures can be reached. Therefore, as was described in Section 2.4., the thickest nanocomposite films $(0.50 \mathrm{~mm})$ were used as energy directors for the ultrasonic welding process, leading to the highest bond line thickness.

\subsubsection{Resistance Heating}

Resistance heating follows Joule's Law, as shown by Equation (4), where $P$ represents Watts of heating, $I$ is the applied current (in A), $V$ is the applied voltage (in V), and $R$ is the electrical resistance (in Ohms) [54].

$$
P=I V=\frac{V^{2}}{R},
$$

As Equation (4) shows, for any given voltage the amount of heating is controlled by the resistance of an object. Therefore, the lower the resistance, the more heat it will generate. Moreover, under a given voltage, thicker films would heat up more because, as shown by Equation (5) below, the resistance of an object will decrease with a larger cross-sectional area:

$$
R=\rho \frac{L}{A},
$$

where $\rho$ is the resistivity, $L$ is the length (in $\mathrm{mm}$ ), and $A$ is the cross-sectional area (in $\mathrm{mm}^{2}$ ). Examples of thermal profiles measured for nanocomposite films containing $15 \mathrm{wt} . \%$ and 20 wt. $\%$ MWCNT are shown in Figure 7. The maximum temperature generally increased with film thickness, CNT weight fraction and applied voltage (Equation (4)). In some cases, slight deviations from this trend were expected based on the large standard deviations seen in Figure 6a and resulting resistance values. At $15 \mathrm{wt} . \% \mathrm{MWCNT}$, maximum temperatures of $58.0^{\circ} \mathrm{C}, 78.7^{\circ} \mathrm{C}$ and $108.0^{\circ} \mathrm{C}$ were obtained at $10 \mathrm{~V}$, for $0.06 \mathrm{~mm}, 0.25 \mathrm{~mm}$ and $0.50 \mathrm{~mm}$ thickness, respectively. On the other hand, at $20 \mathrm{wt} . \%$ MWCNT, maximum temperatures of $80.2^{\circ} \mathrm{C}, 96.1{ }^{\circ} \mathrm{C}$ and $116.0^{\circ} \mathrm{C}$ were obtained at $10 \mathrm{~V}$, for $0.06 \mathrm{~mm}, 0.25 \mathrm{~mm}$ and $0.50 \mathrm{~mm}$ thicknesses, respectively. Figure 8 shows a composite of the measured temperature profiles during the entire Joule heating experiment, when voltage was increased from $2 \mathrm{~V}$ up to $10 \mathrm{~V}$ for all film thicknesses. Maximum temperatures were obtained at $10 \mathrm{~V}$ with $101.6^{\circ} \mathrm{C}$, $102.8^{\circ} \mathrm{C}$ and $120.2^{\circ} \mathrm{C}$ for $0.06 \mathrm{~mm}, 0.25 \mathrm{~mm}$ and $0.50 \mathrm{~mm}$ film thicknesses, respectively.

For the GF/PP adherends and MWCNT/PP films used in this study, their melting temperature $\left(T_{m}\right)$ was measured by differential scanning calorimetry (DSC) in a previous study [36]. The adherends' $T_{m}$ was $150{ }^{\circ} \mathrm{C}$, while the $T_{m}$ of the MWCNT/PP films varied between $141{ }^{\circ} \mathrm{C}$ and $149^{\circ} \mathrm{C}$. For the purpose of disassembly, it is expected an interface temperature close to, or slightly above, this range of temperature should be reached through the energy director (MWCNT/PP film). As previously mentioned in Section 4.1.1, the bond line thickness is expected to be equal to $0.2 \mathrm{~mm}$ at most. Therefore, an applied voltage above $10 \mathrm{~V}$ would be required for disassembly experiments, based on the trends observed in Figures 7 and 8. 

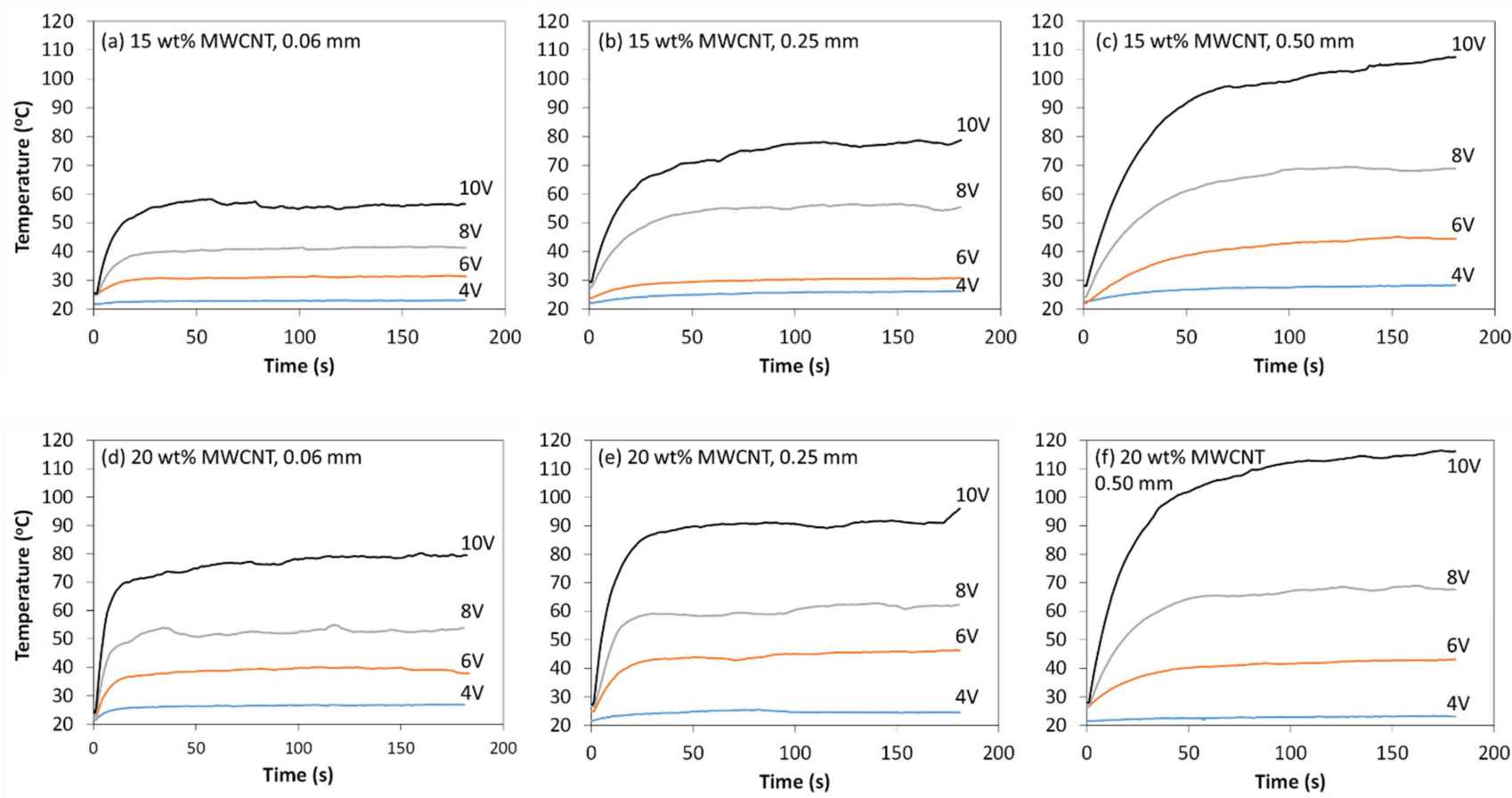

Figure 7. Temperature profiles of MWCNT/PP nanocomposite films at different input voltages and thicknesses: (a-c) $15 \mathrm{wt} . \%$ MWCNT, $0.06 \mathrm{~mm}, 0.25 \mathrm{~mm}$ and $0.50 \mathrm{~mm}$ thicknesses, respectively; and (d-f) $20 \mathrm{wt} . \%$ MWCNT, $0.06 \mathrm{~mm}$, $0.25 \mathrm{~mm}$ and $0.50 \mathrm{~mm}$ thicknesses, respectively.

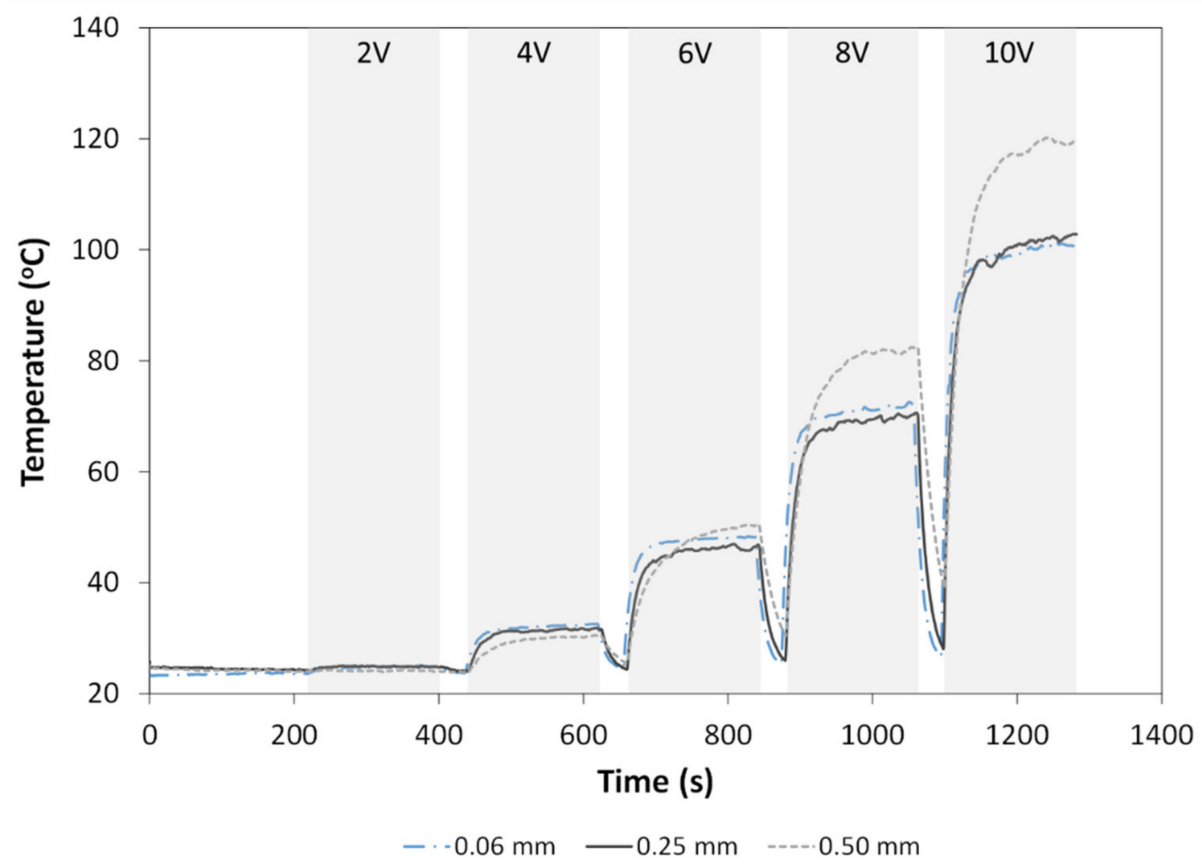

Figure 8. Representative temperature profiles measured for $25 \mathrm{wt} \%$ MWCNT/PP films when voltages from $2 \mathrm{~V}$ to $10 \mathrm{~V}$ are applied for three minutes each.

\subsection{Disassembly Study of Ultrasonically Welded Joints \\ 4.2.1. Tensile Test Results}

Feasibility of the disassembly procedure was assessed and quantified using a tensile testing machine. The lap shear strength (LSS) from load-displacement curves was calculated using the maximum load and the overlap area $(25.4 \mathrm{~mm} \times 127 \mathrm{~mm})$. For each MWCNT weight fraction, disassembly was initiated at three adherend's surface temper- 
atures: $110{ }^{\circ} \mathrm{C}, 130{ }^{\circ} \mathrm{C}$ and $150{ }^{\circ} \mathrm{C}$. Figure 9 summarizes the calculated LSS for all cases and the range of LSS reduction when compared to room temperature tests. It is observed that, as surface temperature increased to $150{ }^{\circ} \mathrm{C}$, the required strength for disassembly was reduced by up to $94 \%$, corresponding to an applied tensile load below $250 \mathrm{~N}$. The lowest surface temperature $\left(110^{\circ} \mathrm{C}\right)$ led to a considerable reduction in LSS, but as the interface temperature likely did not reach melting point, it is not as effective as higher temperatures. At $130{ }^{\circ} \mathrm{C}$, there is a considerable difference between $15 \mathrm{wt} . \%$ MWCNT and $20 \mathrm{wt} . \%$ or $25 \mathrm{wt} . \%$ MWCNT films. There are potentially two causes for this behavior: (1) it was observed that an increase in MWCNT content could lead to lower toughness at the interface for welded joints $[36,39,40]$; (2) due to the slow crosshead speed during disassembly tests $(1.3 \mathrm{~mm} / \mathrm{min})$, the temperature likely continued to increase at the interface, which may have been more significant at higher MWCNT loadings.

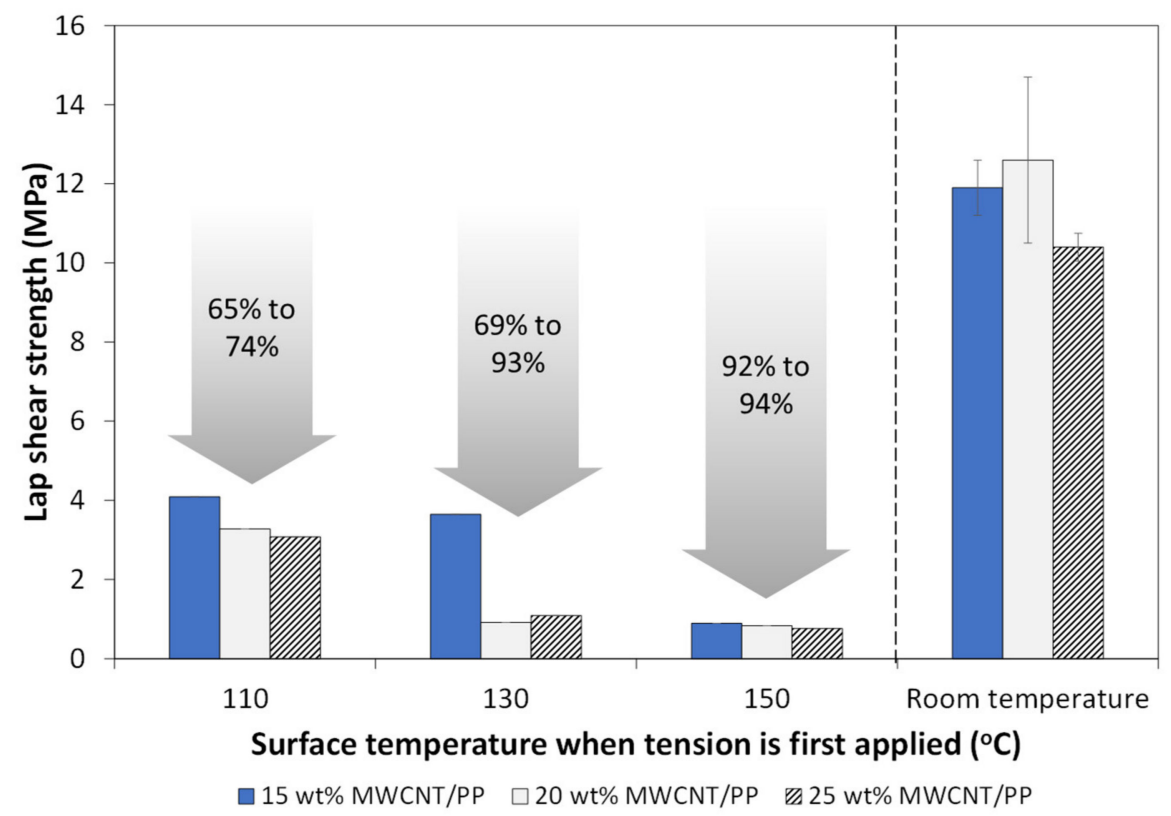

Figure 9. Comparison between lap shear strength of GF/PP welded joints during disassembly procedure when surface temperature reached $110{ }^{\circ} \mathrm{C}, 130^{\circ} \mathrm{C}$ and $150{ }^{\circ} \mathrm{C}$. Interface contained 15 wt. $\%$, $20 \mathrm{wt} . \%$ and $25 \mathrm{wt} . \%$ MWCNT. Room temperature values are used as a reference, as reported in [36].

To further investigate the joints' behavior during disassembly, the shear stress and surface temperature curves were simultaneously plotted with respect to time, as seen in Figure 10. Representative curves are shown for all weight fractions on Figure 10a-c (15 wt. $\%, 20 \mathrm{wt} . \%$ and $25 \mathrm{wt} . \%$ MWCNT), at one surface temperature $\left(110{ }^{\circ} \mathrm{C}, 130{ }^{\circ} \mathrm{C}\right.$ and $150{ }^{\circ} \mathrm{C}$ ). The heat up and disassembly phases are labeled to show the duration of each one. All tests were initiated after less than two minutes (120 s), with the fastest heat up phase for $25 \mathrm{wt} . \%$ MWCNT/PP films. Similarly, the disassembly phase generally lasted less than two minutes. As the applied load increased at the beginning of the disassembly phase, the surface temperature, and by extension, interface temperature, continued to increase as well because the contact at the weld line was not yet severed. However, after failure initiation (at the stress peak), the temperature slowly started to decrease as the integrity of the interface was compromised, leading to fewer conductive paths between MWCNTs. Since the applied voltage was kept constant throughout the disassembly procedure, the temperature consequently decreased. In some cases, as seen in Figure 10c, the disassembly phase displayed an inconsistent stress curve. One possible explanation is that, upon closer inspection of the specimens after disassembly, a small crack defect along the direction of the fibers was found in the adherends at the overlap. As all adherends were visually inspected after welding and no such defect was detected, it is reasonable to assume the crack was created during the disassembly process, likely explaining the inconsistent curves 
seen in Figure 10c. Another explanation is the reduced heating capacity resulting from failure initiation at the interface, and leading to cool down, as observed in the temperature curve. Cool down could contribute to an increase in stress during the process.
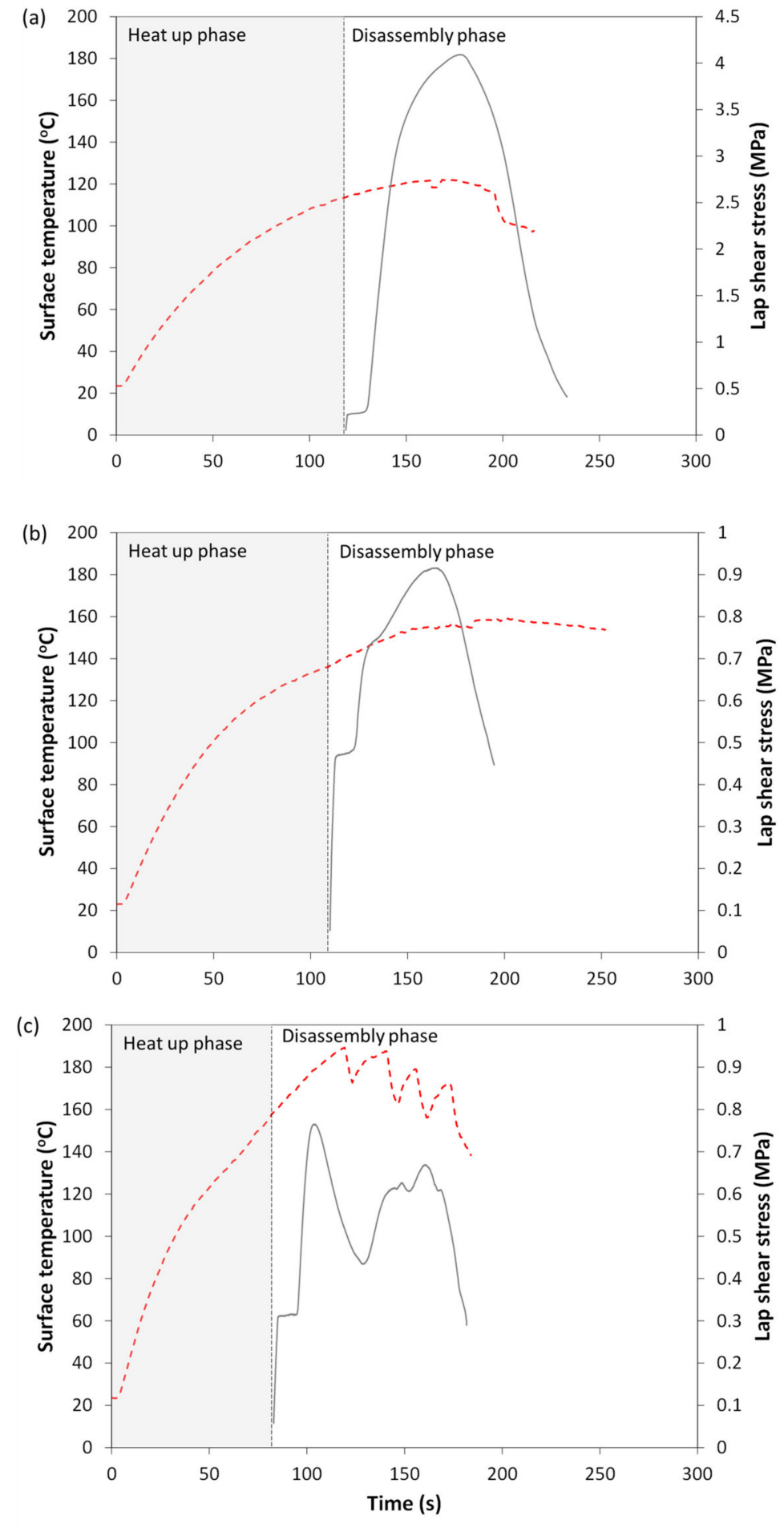

- - - Surface temperature L Lap shear stress

Figure 10. Representative lap shear stress curves (solid lines) of GF/PP welded joints during disassembly procedure with interface containing (a) 15 wt.\% MWCNT at adherend's surface temperatures of $110{ }^{\circ} \mathrm{C}$; (b) 20 wt. \% MWCNT at adherend's surface temperatures of $130{ }^{\circ} \mathrm{C}$; and (c) 25 wt. $\%$ MWCNT at adherend's surface temperatures of $150{ }^{\circ} \mathrm{C}$. Corresponding surface temperature curves are shown as dashed lines. 


\subsubsection{Fractographic and Heat-Affected Zone Analysis}

The fracture surface of the disassembled joints was visually observed after the procedure (Figure 11). Samples are shown as they were immediately after the tests; the welds were not manually separated to avoid influencing the appearance of the fractured joints. The red dashed lines indicate the location of the overlap under heating. Comparison with fracture surfaces at room temperature is shown on the right-hand side. Due to the temperatures reached during disassembly, all welds exhibited ply squeeze out (fiber squeeze out with polymer), as more clearly observed right above the upper dashed line in Figure 11a $\left(110^{\circ} \mathrm{C}\right.$ and $\left.130{ }^{\circ} \mathrm{C}\right)$, Figure $11 \mathrm{~b}\left(110^{\circ} \mathrm{C}\right)$, and Figure $11 \mathrm{C}\left(130^{\circ} \mathrm{C}\right.$ and $\left.150{ }^{\circ} \mathrm{C}\right)$. The visible fracture surfaces exhibit a combination of cohesive and substrate failure modes: intralaminar failure through upper plies, broken fibers in the GF/PP adherend, and failure within the nanocomposite film. The MWCNT/PP films melted at the interface, with the most visible examples marked by the red circled areas in Figure 11b,c.

Figure 12 shows SEM micrographs of fracture surfaces from Figure $11 \mathrm{~b}$ to further analyze microstructure. Welds fractured at room temperature (Figure 12a) mostly displayed broken fibers from the upper plies of the GF/PP adherends, with matrix-fiber debonding and some matrix torn from the fibers' surface. When disassembly temperature increased from $110{ }^{\circ} \mathrm{C}$ to $150^{\circ} \mathrm{C}$ (Figure $12 \mathrm{~b}-\mathrm{d}$ ), fracture surfaces also showed bare, broken fibers, but the thermoplastic matrix exhibited severe softening and drawing behavior with areas that underwent melting and separation from the fibers. As observed in Figure 11b,c, the presence of melted nanocomposite film was confirmed (left-hand SEM images in Figure 12c,d). The porous morphology was shown to be characteristic of the PP matrix under strain [55]. Overall, disassembly at high temperature was facilitated by a combination of melted nanocomposite film at the interface, matrix softening in the adherends, and fibermatrix debonding.

An indication of the extent of the heat-affected zone through the GF/PP adherends thickness is their change in color and opacity (between the dashed, red lines). The polypropylene matrix became transparent at its melting point $\left(150{ }^{\circ} \mathrm{C}\right)$, which is more clearly recognized in Figure $11 \mathrm{~b}$ at $130^{\circ} \mathrm{C}$ and $150^{\circ} \mathrm{C}$. The heat-affected area was quantified using image analysis and is reported in Figure 13 for three images under each parameter combination. The HAZ area increased by up to $97 \%$ with MWCNT content and with initial surface temperature.

\subsection{Discussion on Disassembly Method and Its Limitations}

In this study, it was observed that disassembly temperature, controlled via resistance heating, has an impact on the shear stress of ultrasonically welded joints and their HAZ. This section compares the mechanical behavior, microstructure and HAZ of specimens disassembled at every temperature. The lap shear stress was strongly influenced by the disassembly temperature with a drop up to $74 \%$ at $110{ }^{\circ} \mathrm{C}, 93 \%$ at $130{ }^{\circ} \mathrm{C}$ and $94 \%$ at $150{ }^{\circ} \mathrm{C}$, compared to room temperature (Figure 9). Unlike fracture surfaces at room temperature, as shown in Figure 11, disassembled joints displayed a less uniform surface, indicating the interface reached the melting point, affecting both the nanocomposite film at the interface and the adherends' upper plies. The MWCNT/PP films melted at the bond line, with the most visible examples marked by the red circled areas in Figure 11b,c.

This non-uniformity was confirmed through SEM micrographs, where significant matrix softening and drawing was noted (Figure 12), exhibiting ductile failure. The melting of the nanocomposite film was mostly observed at higher temperatures (Figure 12c,d), with the presence of porosity under temperature and strain increase [55]. Similar matrix drawing was observed for carbon fiber (CF)/PPS joints tested at temperatures above $\mathrm{T}_{\mathrm{g}}$, $120^{\circ} \mathrm{C}$ and $150^{\circ} \mathrm{C}[56,57]$. The joints were manufactured through ultrasonic or resistance welding. In the former case, substantial matrix drawing and ductile fracture was confirmed through SEM micrographs, leading to a decrease in lap shear strength. 


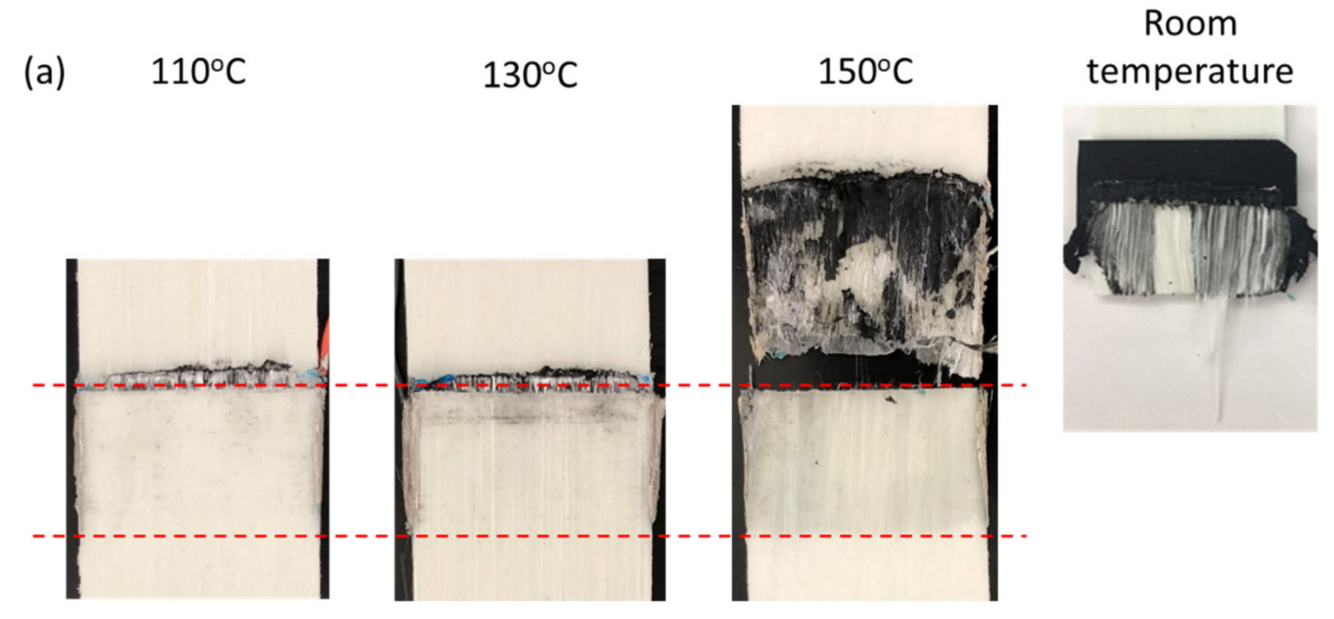

(b) $110^{\circ} \mathrm{C}$

$130^{\circ} \mathrm{C}$

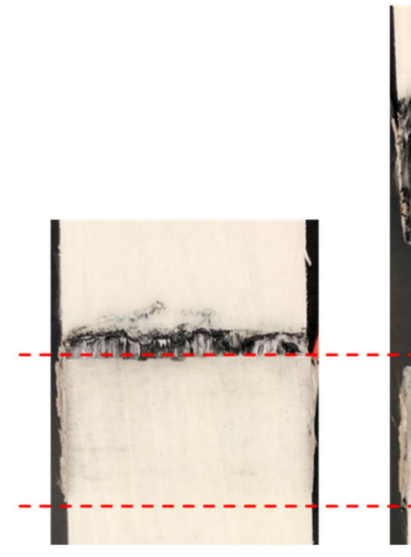

(c) $110^{\circ} \mathrm{C}$

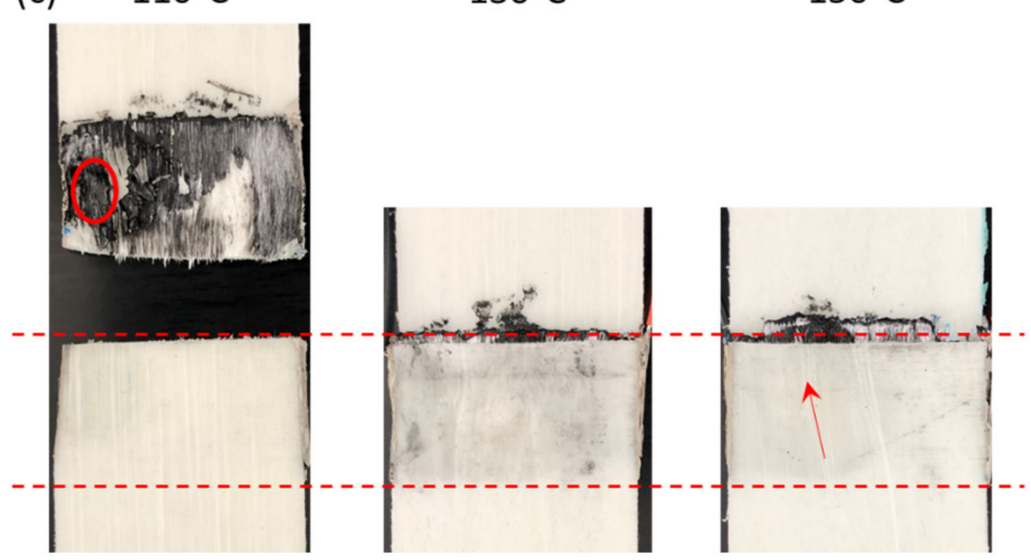

Room

temperature

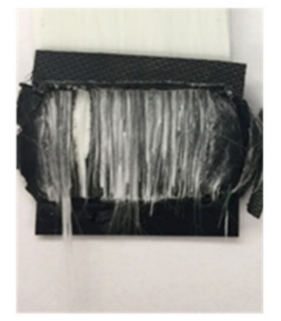

Room

temperature

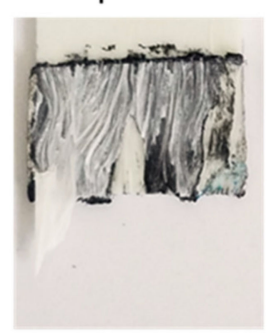

Figure 11. Representative photographic images of welded GF/PP adherends after disassembly procedure: (a) $15 \mathrm{wt} . \%$ MWCNT/PP film; (b) 20 wt.\% MWCNT/PP film, and; (c) 25 wt.\% MWCNT/PP film. The dashed red lines show the location of the overlap for the upper adherend. The circled areas indicate melted nanocomposite films. The arrow in (c) shows the location of a crack in the GF/PP adherend, damaged during the disassembly process. Room temperature images reproduced with permission from [36]. 
(a)

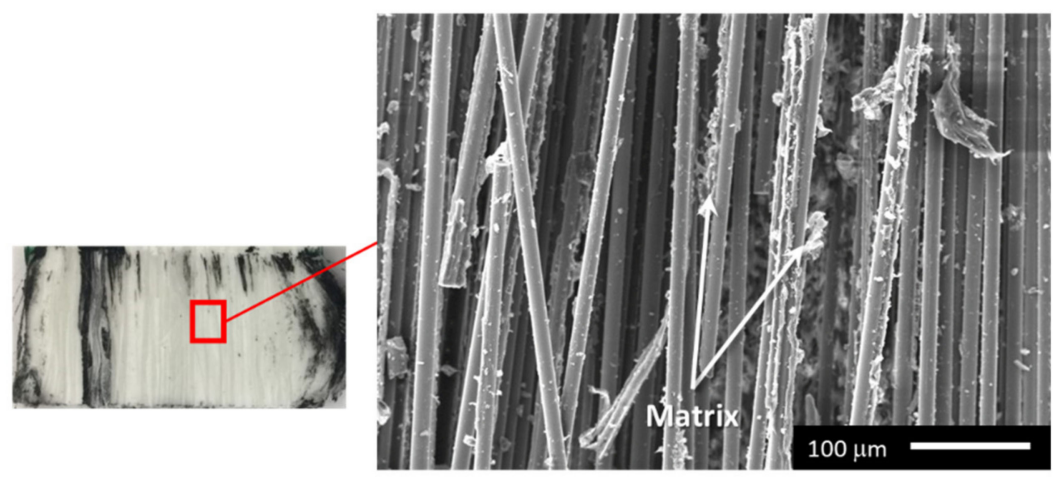

(b)
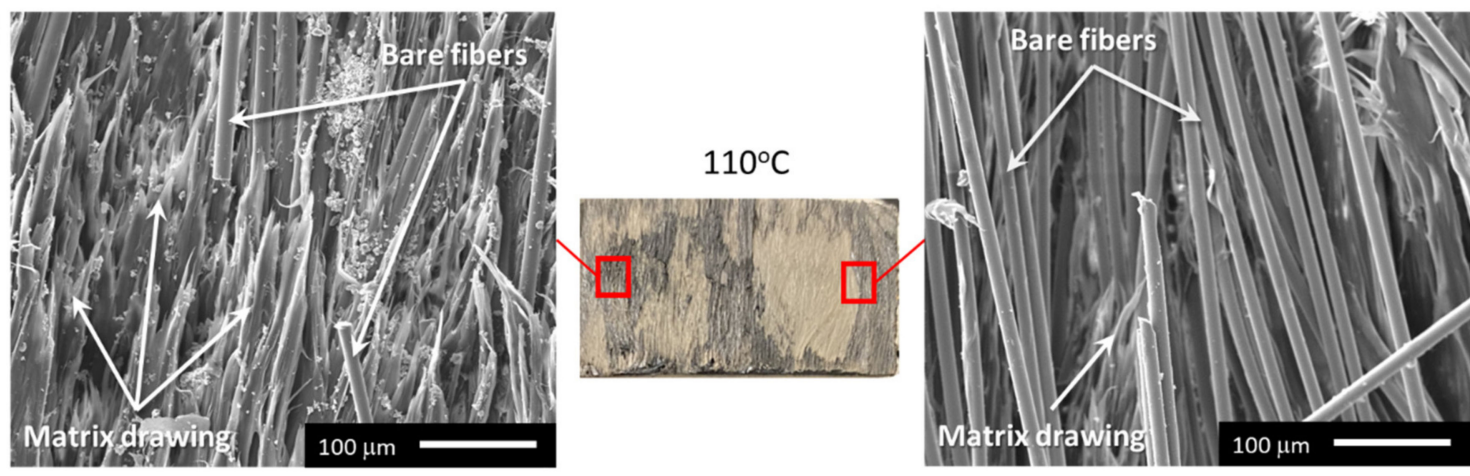

(c)
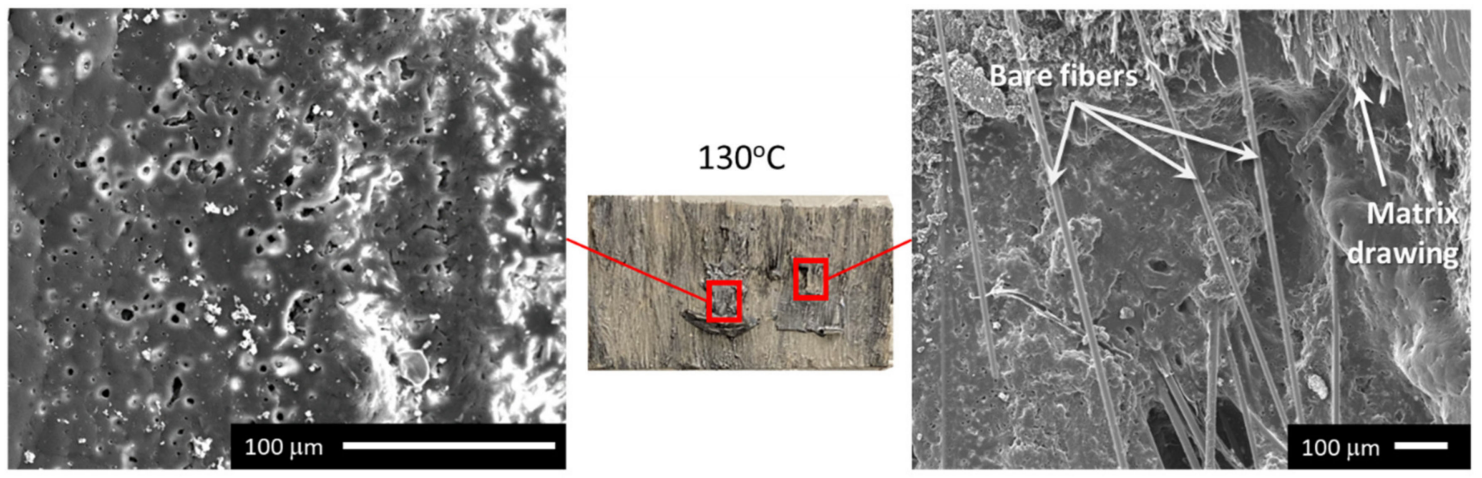

(d)
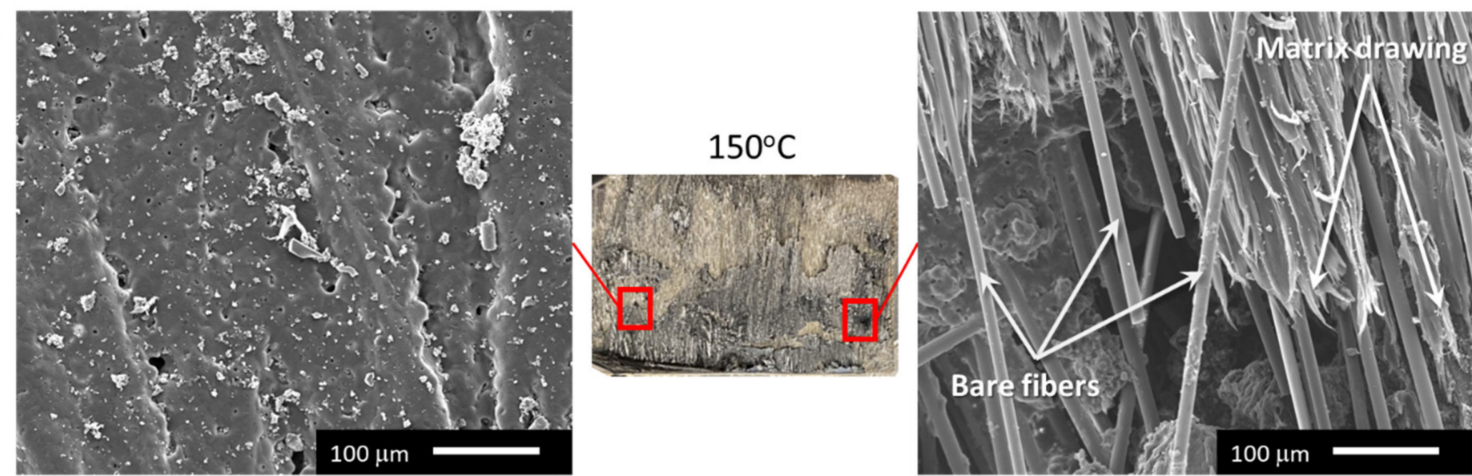

Figure 12. Representative fracture surfaces and SEM micrographs of samples welded with $20 \mathrm{wt} . \%$ MWCNT/PP films after disassembly process: (a) comparison with room temperature fracture surface images, reproduced and modified from [36] with permission; (b) disassembly at $110^{\circ} \mathrm{C}$; (c) disassembly at $130{ }^{\circ} \mathrm{C}$; (d) disassembly at $150{ }^{\circ} \mathrm{C}$. All scale bars are $100 \mu \mathrm{m}$. 


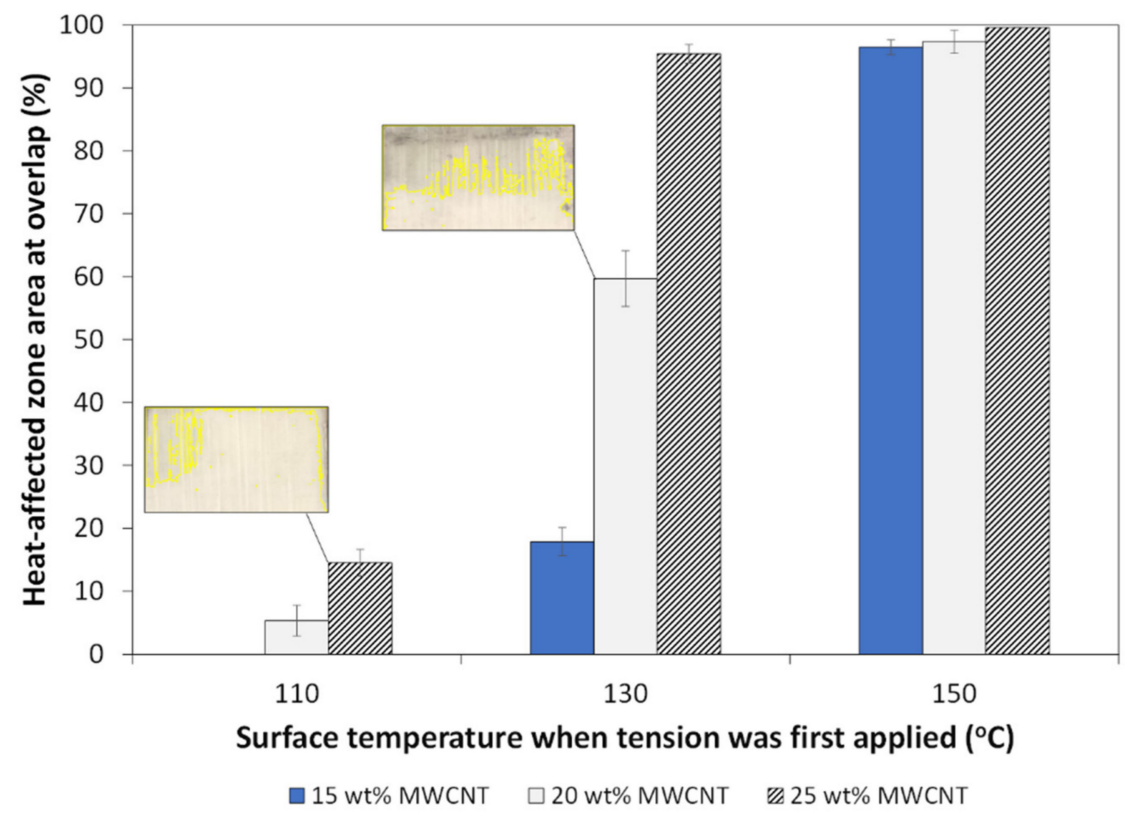

Figure 13. Estimated heat-affected zone area in GF/PP adherends after disassembly procedure at difference surface temperatures, based on adherends' surface color images presented in Figure 11. Two examples of delineated areas are shown in insets.

The HAZ reported in Figure 11, then quantified in Figure 13, is consistent with the temperature curves in Figure $10 \mathrm{~b}, \mathrm{c}$, where a temperature above $150^{\circ} \mathrm{C}$ was reached on the adherend's surface during the disassembly phase. Nonetheless, the experiments confirm resistance heating can facilitate disassembly of ultrasonically welded TPC joints through a manual process, especially at higher weight fractions (20 wt.\% and $25 \mathrm{wt} . \%$ MWCNT) and surface temperatures $\left(130^{\circ} \mathrm{C}\right.$ and $\left.150{ }^{\circ} \mathrm{C}\right)$. Under the parameters investigated in this study, welds disassembled at a surface temperature of $130{ }^{\circ} \mathrm{C}$ with $20 \mathrm{wt} . \%$ MWCNT present the best balance between required shear stress and heat-affected zone.

Given the results presented in this study, a discussion on the limitations of this disassembly method and future work is warranted. It was demonstrated that resistance heating through an electrically conductive nanocomposite film at the welded interface can facilitate joint disassembly by lowering the required shear stress by more than $90 \%$. However, as the process is relatively slow ( $<120 \mathrm{~s}$ heat-up phase) and the total interface/adherends thickness is low $(<4 \mathrm{~mm})$, the heat-affected zone extended through the thickness, mostly at higher temperatures $\left(130{ }^{\circ} \mathrm{C}\right.$ and $\left.150{ }^{\circ} \mathrm{C}\right)$. Consequently, disassembly was not uniquely concentrated at the bond line where the MWCNT/PP film was placed, but affected the GF/PP adherends at the overlap as well. Thus, the method might be better suited for recycling at end-of-life or reuse of components by cutting off the damaged overlap section.

Finally, as the interface was structurally compromised during disassembly, it partially affected the efficiency of resistance heating. It is expected that a faster cross-head speed during disassembly, use of highest MWCNT weight fractions (such as $20 \mathrm{wt} . \%$ or $25 \mathrm{wt} . \%$ ) and control of the applied voltage during the process could mitigate this limitation, as well as the extent of the HAZ. A faster cross-head speed would reduce the time between the beginning of the disassembly phase and the peak in the stress curves (Figure 10), as well as the overall duration of the disassembly phase. Therefore, the temperature when failure initiates and propagates at maximum stress would be lower, potentially limiting the HAZ in the adherends. Further, if failure were to occur at a faster rate, the interface might not have time to cool down due to lower heating efficiency. Some future research directions include (1) investigation of disassembly parameters (e.g., crosshead speed, voltage regulation through constant power output [39]); (2) use of thicker adherends to investigate HAZ; (3) healing of bond-line defects/damage through resistance heating. 


\section{Conclusions}

In this work, it was demonstrated that resistance heating via an electrically conductive MWCNT/PP film at the welded interface facilitated ultrasonic joint disassembly of TPCs. Three MWCNT fractions were characterized for thermo-electrical behavior with applied voltages up to $10 \mathrm{~V}$. A maximum temperature of $120^{\circ} \mathrm{C}$ was reached at the highest MWCNT loading and applied voltage. For disassembly experiments, tests were initiated when the surface temperature of the GF/PP adherend reached either $110^{\circ} \mathrm{C}, 130^{\circ} \mathrm{C}$ or $150{ }^{\circ} \mathrm{C}$. The shear stress during disassembly decreased by at least $93 \%$ at the highest MWCNT weight fraction and surface temperature, compared to room temperature testing. Analysis of fracture surfaces after disassembly revealed the melting of both MWCNT films and the adherends' matrix at the overlap with significant matrix drawing and fiber-matrix debonding, effectively facilitating disassembly. At higher temperatures and MWCNT weight fractions, the heat-affected zone extended through the thickness of the adherends, owing to the low cross-head speed and the duration of the disassembly phase $(<120 \mathrm{~s})$ during which heat transfer occurred. In order to minimize the extent of the heat-affected zone area $(<60 \%)$, while maximizing ease of assembly, a surface temperature of $130{ }^{\circ} \mathrm{C}$ with $20 \mathrm{wt} . \%$ MWCNT films would be recommended for the parameters investigated in this study.

Overall, this study confirmed the feasibility of this disassembly method for the first time in the literature. However, this might be better suited for recycling at end-of-life or reuse of components by cutting off the heat-affected overlap section. Moreover, as the interface was structurally compromised during disassembly, it affected the efficiency of resistance heating. Faster crosshead speeds during disassembly, the use of the highest MWCNT weight fractions, and control of the applied voltage during the process could, however, mitigate these limitations.

Author Contributions: Conceptualization, H.F. and G.P.; funding acquisition, G.P.; methodology, analysis and investigation, H.F. and W.L.; validation, H.F. and G.P.; writing-original draft preparation, H.F. and G.P.; writing-review and editing, G.P. and W.L.; visualization, H.F., G.P. and W.L.; supervision, G.P. All authors have read and agreed to the published version of the manuscript.

Funding: This research was funded by the Louisiana Board of Regents under the Research Competitiveness Subprogram (contract number LEQSF (2018-2022)-RD-A-05) with partial funding from the LaSPACE Research Enhancement Award (award number 002379) and the LSU Graduate School Economic Development Assistantship.

Data Availability Statement: Not applicable.

Acknowledgments: The authors would like to acknowledge Mark Brennan for his assistance with tensile tests.

Conflicts of Interest: The authors declare no conflict of interest. The funders had no role in the design of the study; in the collection, analyses, or interpretation of data; in the writing of the manuscript, or in the decision to publish the results.

\section{References}

1. Cousins, D.S.; Suzuki, Y.; Murray, R.E.; Samaniuk, J.R.; Stebner, A. Recycling glass fiber thermoplastic composites from wind turbine blades. J. Clean. Prod. 2019, 209, 1252-1263. [CrossRef]

2. Li, Y.; Liu, Z.; Shen, J.; Lee, T.H.; Banu, M.; Hu, S.J. Weld quality prediction in ultrasonic welding of carbon fiber composite based on an ultrasonic wave transmission model. J. Manuf. Sci. Eng. 2019, 141, 081010. [CrossRef]

3. Yousefpour, A.; Hojjati, M.; Immarigeon, J.-P. Fusion Bonding/Welding of Thermoplastic Composites. J. Thermoplast. Compos. Mater. 2004, 17, 303-341. [CrossRef]

4. Arnt, O.; van Ingen, J.W.; Buitenhuis, A. Development of a butt jointed thermoplastics stiffened shin concept. In Proceedings of the SAMPE Conference, Long Beach, CA, USA, 23-26 May 2011.

5. Agarwal, B.D.; Broutman, L.J.; Chandrashekhara, K. Analysis and Performance of Fiber Composites, 4th ed.; John Wiley \& Sons, Inc.: Hoboken, NJ, USA, 2018. 
6. Murray, R.E.; Penumadu, D.; Cousins, D.; Beach, R.; Snowberg, D.; Berry, D.; Suzuki, Y.; Stebner, A. Manufacturing and Flexural Characterization of Infusion-Reacted Thermoplastic Wind Turbine Blade Subcomponents. Appl. Compos. Mater. 2019, 26, 945-961. [CrossRef]

7. Reis, J.P.; de Moura, M.; Samborski, S. Thermoplastic Composites and Their Promising Applications in Joining and Repair Composites Structures: A Review. Materials 2020, 13, 5832. [CrossRef]

8. Engelschall, M.; Larsen, L.; Fischer, F.; Kupke, M. Robot-based continuous ultrasonic welding for automated production of aerospace structures. In Proceedings of the SAMPE Europe Conference, Nantes, France, 17-19 September 2019.

9. Jongbloed, B.; Teuwen, J.; Benedictus, R.; Villegas, I.F. On differences and similarities between static and continuous ultrasonic welding of thermoplastic composites. Compos. Part B Eng. 2020, 203, 108466. [CrossRef]

10. Bhudolia, S.K.; Gohel, G.; Leong, K.F.; Barsotti, R.J. Investigation on Ultrasonic Welding Attributes of Novel Carbon/Elium ${ }^{\circledR}$ Composites. Materials 2020, 13, 1117. [CrossRef] [PubMed]

11. Villegas, I.F.; Moser, L.; Yousefpour, A.; Mitschang, P.; Bersee, H.E. Process and performance evaluation of ultrasonic, induction and resistance welding of advanced thermoplastic composites. J. Thermoplast. Compos. Mater. 2013, 26, 1007-1024. [CrossRef]

12. Benatar, A.; Eswaran, R.V.; Nayar, S.K. Ultrasonic welding of thermoplastics in the near-field. Polym. Eng. Sci. 1989, 29, 1689-1698. [CrossRef]

13. Zhang, Z.; Xiaodong, W.; Yi, L.; Zhenqiang, Z.; Liding, W. Study on Heating Process of Ultrasonic Welding for Thermoplastics. J. Thermoplast. Compos. Mater. 2010, 23, 647-664. [CrossRef]

14. Bhudolia, S.K.; Gohel, G.; Kantipudi, J.; Leong, K.F.; Barsotti, R.J. Ultrasonic Welding of Novel Carbon/Elium ${ }^{\circledR}$ Thermoplastic Composites with Flat and Integrated Energy Directors: Lap Shear Characterisation and Fractographic Investigation. Materials 2020, 13, 1634. [CrossRef] [PubMed]

15. Tao, W.; Su, X.; Wang, H.; Zhang, Z.; Li, H.; Chen, J. Influence mechanism of welding time and energy director to the thermoplastic composite joints by ultrasonic welding. J. Manuf. Process. 2019, 37, 196-202. [CrossRef]

16. Palardy, G.; Villegas, I.F. On the effect of flat energy directors thickness on heat generation during ultrasonic welding of thermoplastic composites. Compos. Interfaces 2016, 24, 203-214. [CrossRef]

17. Villegas, I.F.; Bersee, H.E.N. Ultrasonic welding of advanced thermoplastic composites: An investigation on energy-directing surfaces. Adv. Polym. Technol. 2010, 29, 112-121. [CrossRef]

18. Yan, J.; Wang, X.; Li, R.; Xu, H.; Yang, S. The Effects of Energy Director Shape on Temperature Field During Ultrasonic Welding of Thermoplastic Composites. Key Eng. Mater. 2007, 353-358, 2007-2010. [CrossRef]

19. Bhudolia, S.K.; Gohel, G.; Leong, K.F.; Islam, A. Advances in Ultrasonic Welding of Thermoplastic Composites: A Review. Materials 2020, 13, 1284. [CrossRef] [PubMed]

20. Choudhury, M.R.; Debnath, K. Analysis of tensile failure load of single-lap green composite specimen welded by high-frequency ultrasonic vibration. Mater. Today Proc. 2020, 28, 739-744. [CrossRef]

21. Bhudolia, S.K.; Gohel, G.; Kah, F.L.; Barsotti, R.J. Fatigue response of ultrasonically welded carbon/Elium ${ }^{\circledR}$ thermoplastic composites. Mater. Lett. 2020, 264, 127362. [CrossRef]

22. Jongbloed, B.; Teuwen, J.; Palardy, G.; Villegas, I.F.; Benedictus, R. Continuous ultrasonic welding of thermoplastic composites: Enhancing the weld uniformity by changing the energy director. J. Compos. Mater. 2020, 54, 2023-2035. [CrossRef]

23. Goto, K.; Imai, K.; Arai, M.; Ishikawa, T. Shear and tensile joint strengths of carbon fiber-reinforced thermoplastics using ultrasonic welding. Compos. Part A Appl. Sci. Manuf. 2019, 116, 126-137. [CrossRef]

24. Kalyan Kumar, R.; Omkumar, M. Investigation and characterization of ultrasonically welded GF/PA6T composites. Mater. Today Proc. 2019, 26, 282-286. [CrossRef]

25. Tutunjian, S.; Dannemann, M.; Fischer, F.; Eroglu, O.; Modler, N. A Control Method for the Ultrasonic Spot Welding of FiberReinforced Thermoplastic Laminates through the Weld-Power Time Derivative. J. Manuf. Mater. Process. 2018, 3, 1. [CrossRef]

26. Villegas, I.F.; Palardy, G. Ultrasonic welding of CF/PPS composites with integrated triangular energy directors: Melting, flow and weld strength development. Compos. Interfaces 2017, 24, 515-528. [CrossRef]

27. Tutunjian, S.; Dannemann, M.; Modler, N.; Kucher, M. A Numerical Analysis of the Temporal and Spatial Temperature Development during the Ultrasonic Spot Welding of Fibre-Reinforced Thermoplastics. J. Manuf. Mater. Process. 2020, 4, 30. [CrossRef]

28. Koutras, N.; Amirdine, J.; Boyard, N.; Villegas, I.F.; Benedictus, R. Characterisation of Crystallinity at the Interface of Ultrasonically Welded Carbon Fibre PPS Joints. Compos. Part A Appl. Sci. Manuf. 2019, 125, 105574. [CrossRef]

29. Li, Y.; Yu, B.; Wang, B.; Lee, T.H.; Banu, M. Online quality inspection of ultrasonic composite welding by combining artificial intelligence technologies with welding process signatures. Mater. Des. 2020, 194, 108912. [CrossRef]

30. Lionetto, F.; Dell'Anna, R.; Montagna, F.; Maffezzoli, A. Modeling of continuous ultrasonic impregnation and consolidation of thermoplastic matrix composites. Compos. Part A Appl. Sci. Manuf. 2016, 82, 119-129. [CrossRef]

31. Palardy, G.; Shi, H.; Levy, A.; Le Corre, S.; Villegas, I.F. A study on amplitude transmission in ultrasonic welding of thermoplastic composites. Compos. Part A Appl. Sci. Manuf. 2018, 113, 339-349. [CrossRef]

32. Levy, A.; Le Corre, S.; Poitou, A. Ultrasonic welding of thermoplastic composites: A numerical analysis at the mesoscopic scale relating processing parameters, flow of polymer and quality of adhesion. Int. J. Mater. Form. 2014, 7, 39-51. [CrossRef]

33. Levy, A.; Le Corre, S.; Villegas, I.F. Modeling of the heating phenomena in ultrasonic welding of thermoplastic composites with flat energy directors. J. Mater. Process. Technol. 2014, 214, 1361-1371. [CrossRef] 
34. Suresh, K.S.; Rani, M.R.; Prakasan, K.; Rudramoorthy, R. Modeling of temperature distribution in ultrasonic welding of thermoplastics for various joint designs. J. Mater. Process. Technol. 2007, 186, 138-146. [CrossRef]

35. Wang, X.; Yan, J.; Li, R.; Yang, S. FEM Investigation of the Temperature Field of Energy Director During Ultrasonic Welding of PEEK Composites. J. Thermoplast. Compos. Mater. 2006, 19, 593-607. [CrossRef]

36. Li, W.; Frederick, H.; Palardy, G. Multifunctional films for thermoplastic composite joints: Ultrasonic welding and damage detection under tension loading. Compos. Part A Appl. Sci. Manuf. 2021, 141, 106221. [CrossRef]

37. Frederick, H.; Li, W.; Sands, W.; Tsai, E.; Palardy, G. Multifunctional films for fusion bonding and structural health monitoring of thermoplastic composite joints. In Proceedings of the SAMPE Conference, Charlotte, NC, USA, 6 July 2020.

38. Brassard, D.; Dubé, M.; Tavares, J.R. Modelling resistance welding of thermoplastic composites with a nanocomposite heating element. J. Compos. Mater. 2020, 55, 625-639. [CrossRef]

39. Brassard, D.; Dubé, M.; Tavares, J.R. Resistance welding of thermoplastic composites with a nanocomposite heating element. Compos. Part B Eng. 2019, 165, 779-784. [CrossRef]

40. Farahani, R.D.; Janier, M.; Dubé, M. Conductive films of silver nanoparticles as novel susceptors for induction welding of thermoplastic composites. Nanotechnology 2018, 29, 125701. [CrossRef] [PubMed]

41. Farahani, R.D.; Dubé, M. Novel Heating Elements for Induction Welding of Carbon Fiber/Polyphenylene Sulfide Thermoplastic Composites. Adv. Eng. Mater. 2017, 19, 1700294. [CrossRef]

42. Vattathurvalappil, S.H.; Hassan, S.F.; Haq, M. Healing potential of reversible adhesives in bonded joints. Compos. Part B Eng. 2020, 200, 108360. [CrossRef]

43. Vattathurvalappil, S.H.; Haq, M. Thermomechanical characterization of $\mathrm{Nano}_{-} \mathrm{Fe}_{3} \mathrm{O}_{4}$ reinforced thermoplastic adhesives and single lap-joints. Compos. Part B Eng. 2019, 175, 107162. [CrossRef]

44. Ashrafi, B.; Laqua, K.; Martinez-Rubi, Y.; Jakubinek, M.B.; Park, D.; Simard, B. Electrically responsive polyurethane-CNT sheets for sensing and heating. In Proceedings of the CANCOM 2017, Ottawa, ON, Canada, 17-20 July 2017.

45. Martinez-Rubi, Y.; Ashrafi, B.; Jakubinek, M.B.; Zou, S.; Laqua, K.; Barnes, M.; Simard, B. Fabrication of High Content Carbon Nanotube-Polyurethane Sheets with Tailorable Properties. ACS Appl. Mater. Interfaces 2017, 9, 30840-30849. [CrossRef]

46. Senders, F.; van Beurden, M.; Palardy, G.; Villegas, I.F. Zero-flow: A novel approach to continuous ultrasonic welding of CF/PPS thermoplastic composite plates. Adv. Manuf. Polym. Compos. Sci. 2016, 2, 83-92. [CrossRef]

47. Almasri, A.M. Predicting the thermal conductivity of polypropylene-multiwall carbon nanotubes using the Krenchel model. Sci. Eng. Compos. Mater. 2018, 25, 383-388. [CrossRef]

48. Kim, P.; Shi, L.; Majumdar, A.; McEuen, P.L. Thermal Transport Measurements of Individual Multiwalled Nanotubes. Phys. Rev. Lett. 2001, 87, 215502. [CrossRef] [PubMed]

49. Pan, Y.; Li, L.; Chan, S.H.; Zhao, J. Correlation between dispersion state and electrical conductivity of MWCNTs/PP composites prepared by melt blending. Compos. Part A Appl. Sci. Manuf. 2010, 41, 419-426. [CrossRef]

50. Ramírez-Herrera, C.A.; Pérez-González, J.; Solorza-Feria, O.; Romero-Partida, N.; Flores-Vela, A.; Cabañas-Moreno, J.G. Highest recorded electrical conductivity and microstructure in polypropylene-carbon nanotubes composites and the effect of carbon nanofibers addition. Appl. Nanosci. 2018, 8, 1221-1232. [CrossRef]

51. Gulrez, S.; Ali Mohsin, M.E.; Shaikh, H.; Anis, A.; Poulose, A.M.; Yadav, M.K.; Qua, E.H.P.; Al-Zahrani, S.M. A review on electrically conductive polypropylene and polyethylene. Polym. Compos. 2014, 35, 900-914. [CrossRef]

52. Nanni, F.; Mayoral, B.L.; Madau, F.; Montesperelli, G.; McNally, T. Effect of MWCNT alignment on mechanical and self-monitoring properties of extruded PET-MWCNT nanocomposites. Compos. Sci. Technol. 2012, 72, 1140-1146. [CrossRef]

53. Jang, S.-H.; Park, Y.-L. Carbon nanotube-reinforced smart composites for sensing freezing temperature and deicing by self-heating. Nanomater. Nanotechnol. 2018, 8. [CrossRef]

54. Stavrov, D.; Bersee, H.E.N. Resistance welding of thermoplastic composites-an overview. Compos. Part A Appl. Sci. Manuf. 2005, 36, 39-54. [CrossRef]

55. Etcheverry, M.; Barbosa, S.E. Glass Fiber Reinforced Polypropylene Mechanical Properties Enhancement by Adhesion Improvement. Materials 2012, 5, 1084-1113. [CrossRef]

56. Rohart, V.; Lebel, L.L.; Dubé, M. Effects of environmental conditions on the lap shear strength of resistance-welded carbon fibre/thermoplastic composite joints. Compos. Part B Eng. 2020, 198, 108239. [CrossRef]

57. Koutras, N.; Benedictus, R.; Villegas, I.F. Thermal effects on the performance of ultrasonically welded CF/PPS joints and its correlation to the degree of crystallinity at the weldline. Compos. Part C Open Access 2021, 4, 100093. [CrossRef] 